ON SOME EFFECTS

or

INFLAMMATION

or

THE MEMBRANOUS LINING

or

\title{
THE LARY NX;
}

WITH SUGGESTIONS

RELATIVE TO

THE OPERATION OF BRONCHOTOMY;

AND

INCIDENTAL REMARKS

ON SPASM AND WOUNDS OF THE THROAT.

BY JOH W WOOD,

LATE HOUSE-SURGEON TO ST. BARTHOLOMEW'S HOSPITAL.

COMMUNICATED BY W. LAWRENCE, ESQ.

READ FEBRUARY 14TH A D 28TH, AND MARCH 13TH.

\section{PART I.-LARYNGITIS.}

INFLAMMATION with swelling and thickening of the mucous membrane of the larynx, and of the subjacent cellular tissue, is not very uncommon; and it strongly claims our attention from the suddenness with which its alarming symptoms often appear, and the rapidity with which a fatal result is frequently produced. This disease occurs chiefly in adults. In many cases it comes on almost insensibly, and pro- 
ceeds slowly. It is not usually complicated with inflammation of the tracheal or bronchial lining, or with inflammatory fever*. In its acute form it is generally attended with complete dysphagia, and in milder cases with impaired deglutition in a less degree. By these peculiarities it may be distinguished from croup; and, when examined pathologically, its effects are found to differ from those of croup, inasmuch as the change of structure consists of interstitial deposition, and not of effusion in the form of an adventitious membrane upon the surface of the inflamed mucous coat $\psi$.

Little doubt can be entertained that the writers

* “In angina membranacea febris concomitans inflammatoria est: in serosa febris comitans pituitosa, sæpe nervosa est." Goelis, Tractatus de rite Cognoscenda et Sananda Angina Membranacea.-Viennæ, p. 53.

Dr. Hecker states, that in the angina pituitosa, vel odematosa, there is generally either a complete absence of fever, or the accompanying fever is either catarrhal or exanthematic. Von den Entzündungen im Halse, \&c.-Berlin, 1809, p. 92.

+ After certain forms of inflammation of the larynx, which essentially differ in their nature from croup, it is not uncommon to find a few distinct and delicate portions of adventitious membrane on the mucous surface : but these do not constitute the predominant morbid alteration. Such membranes have often been observed in co-existence with œdema of the glottis.

Dr. Bricheteau asserts, that sometimes a portion of false membrane contracts adhesions with the membrane of the windpipe, and constitutes, a long time after the termination of an attack of croup, a particular kind of affection. (Précis Analytique du Croup, \&c., p. 345. Paris, 1826.) Is the deposition which characterizes croup capable of organization and growth? 
referred to by Dr. Goelis * as authorities that croup may attack persons of the age of forty and sixty, were mistaken in the nature of the affection which they considered to be croup $\uparrow$. This talented physician, in deference to the opinions of certain authors, and not in consequence of having himself seen any case of croup at so advanced a period of life, states that no age is exempt from this disease ("nulli vitæ periodo hic morbus parcit.") Dr. Goelis adds, however, " præprimis tamen ætas infantilis a primo ad septimum ætatis annum ad eum est proclivis.” He mentions that he treated a child at the breast, five months old, and refers to other instances of croup in sucklings. Dugès $\ddagger$ states that he has seen this disease in an infant eight days old.

"In no part of Britain, I imagine," says Dr. Cheyne $\$$, "is croup more prevalent than in Leith and its immediate neighbourhood; yet, in the course of nearly fifty years of extensive practice, in which he has

* Lib. cit.

+ It is clear that Valentin was deceived in this point. He mentions the case of Dr. Pitcairn, as a proof that croup may occur at the age of sixty. In the third volume of the Journal Hebdomadaire, .1829, there is given, under the inappropriate title of "Observation sur un Croup d'Adulte," the history of a patient, named Antoine, who died at the age of twenty-six, of a protracted inflammation of the glottis, brought on by excessive indulgence in spirit drinking and other intemperate habits.

$\ddagger$ Dict. de Méd. et Chir. Tom. V. p. 569.

$\S$ On the Pathology of the Membrane of the Larynx and Bronchia, p. 27. 
attended many hundred cases of this disease, my father has not seen one instance of croup occurring after puberty, while he has attended many cases between the tenth and fourteenth year, both in delicate and robust children." Mr. Double*, who never had occasion, himself, to observe croup in an adult, admits, after a careful examination of recorded facts, that it may sometimes happen after puberty, but that the occurrence is much rarer than has been supposed. Dr. Mills $\uparrow$ records a case of croup which proved fatal, in a Miss - - aged twenty-six. "The lining membrane of the trachea and bronchi, was found inflamed, and covered with coagulable lymph." On dissecting the body of a girl, aged twenty, who died suffocated after a few days' suffering, Mr. Latour $\ddagger$ found a membranous coating (couenne membraneuse) extending from the larynx to the division of the bronchia. Such unequivocal examples of the occurrence of croup at so late a period of life are; I believe, extremely rare.

The specimens of croup which I have seen in collections of morbid anatomy, induce me to mistrust the statements of Dr. Craigie $\S$, that “ it rarely affects the laryngeal membrane;" and that " the inflammation is seated in the tracheo-bronchial membrane

* Traité du Croup, p. 281. Paris, 1811.

+ On the Morbid Appearances of the Trachea, \&c., p. 7. Dublin, 1829.

$\ddagger$ Manuel sur le Croup, p. 16.

$\S$ Elements of General and Pathological Anatomy, p. 676. 
solely." Bichat* and other French pathologists have come to a very different conclusion respecting the seat of croup. Dr. Desruelles $\uparrow$ contends that it is essentially a disease of the larynx. Messrs. Roche and Sanson $\ddagger$ maintain that croup affects, almost always, the larynx and trachea. Dr. Bland $\S$, who, like myself, adopts the latter opinion, has accordingly denominated this affection laryngo-tracheite, a name which Dr. Desruelles has, I think, decried unreasonably.

The distinction of croup from other forms of inflammation of the larynx, and an accurate knowledge of the seat of obstruction in each instance, are essential to successful treatment of the different affections. General bleeding, so highly beneficial in croup, seems often to have aggravated the sufferings, and hastened the death, of those affected with oedema of the glottis. Had the pathology of croup been better understood, laryngotomy would never have been declared to be the most efficacious means of relief.

In parts where cellular tissue abounds without any admixture of adipous substance, swelling is produced by different degrees of inflammation. The scrotum,

* Anatomie Pathologique, p. 97. Paris, 1825.

+ Traité du Croup, p. 113. Paris, 1824.

$\ddagger$ Nouveaux Elémens de Pathologie Medico-Chirurgicale; Tom. I., p. 383. Paris, 1828.

$\S$ Nouvelles Recherches sur la Laringo-Trachéite, connue sur le nom de Croup. Paris, 1823. 
for instance, may be thickened and enlarged by slow inflammation; or it may become tense and swelled by serous effusion, from active inflammatory affection. The like changes are observed in the prepuce and conjunctiva. They seem to exist also in the analogous submucous membrane of the glottis, according as it is acutely or slowly inflamed. "In many instances," says Dr. Craigie, "the margins of the glottis are occupied by an oedematous or puffy swelling, similar to that which occasionally affects the eyelids, prepuce, and female labia,-from sero-albuminous infiltration of the submucous filamentous tissue, and the effect of which is to diminish, or in some instances to obliterate, the aperture which regulates the admission of air into the trachea." *

To prevent obstruction in the mucous passages from accumulation of fat, the submucous membrane is reticular. This tissue is in small quantity and compact where it unites a mucous membrane to cartilage or bone,-more abundant and loose between such a membrane and other. soft parts. In the larynx, where it abounds most at the root of the epiglottis and near the vocal ligaments, it was stated by Bichat $\uparrow$ to be susceptible of serous infiltration, which might rapidly cause suffocation. In every such instance seen by Andral, a well characterized chronic

* Lib. cit.

+ Anatomie Descriptive, Tom. II. p. 399. 
inflammation had existed, and the œdema was a mere secondary phenomenon*. The previous disorder of the membrane may here, perhaps, have been merely increased by the supervention of a fresh exciting cause of inflammation, such as exposure to cold, improper diet, or any such source of aggravation $\uparrow$. In other instances the chronic forms of the disease may supervene to the acute. OEdema of the glottis seldom occurs as a primary acute inflammatory affection. It is generally preceded, sometimes followed, by a mild form of inflammation.

The swollen membrane may be indurated, or softened, or have its usual consistence. Dr. Cheyne has found it "like a thin layer of flexible cartilage." $\$$ Softening of the aerial mucous texture is

* Clinique Médicale, Tom. II., p. 206.-Andral admits, that " œdema of the glottis may occur as an idiopathic disease; but this is not the most common case, and it is ordinarily connected with acute inflammation (hyperémie aiguë) of the mucous membrane of the larynx. It is often developed during the course of chronic affections of this organ. It may be formed slowly, and never extend considerably, nor interfere much with respiration. At other times its rapid and great development suddenly produces asphyxia and death."-Précis d'Anatomie Pathologique, Tom. II. p. 495.

+ “There exists always," says Dr. Albers, " in connexion with chronic inflammation a second disease, and one, indeed, which causes inflammation in the weakened part whenever a fresh source of irritation is superinduced."-Die Pathologie und Therapie der Kehlkopfskrankheiten, p. 69.

$\ddagger$ Lib. cit. p. 175 . 
much rarer than of the intestinal, but frequently occurs in the larynges of phthisical subjects *.

It is often impossible to determine, during life, whether acute inflammation has caused serous effusion into the submucous tissue, or whether this part is swollen and thickened by gradual interstitial deposition. In his valuable "Observations on the Surgical Pathology of the Larynx and Trachea," Mr. Porter states, that the symptoms of chronic cynanche laryngea resemble in every respect those of laryngitis œdematosa ; that the former inflammation commences so insidiously, and proceeds so slowly, as often to produce an incurable disease before the patient's attention is roused to the perilous nature of his condition ; and that the latter is also, occasionally, very. insidious in its approach. Two young men, who had retired to bed at night without complaining, were found dead from this affection the next morning $\uparrow$.

A modification of inflammatory action may produce a combination of both affections, and thus constitute an intermediate distinction, (LARYNGITIS CHRONICA cedematosa,) - a variety described by Mr. Lawrence in the sixth volume of the Society's Transactions.

Inflammation of the membrane of the larynx may end in suppuration $\ddagger$ : this occasionally happens in

* Clinique Médicale, Tom. II. p. 192.

+ Porter's Observations, \&c., pp. 95, 115, and 123.

$\ddagger$ See the case of a shoemaker, aged seventy-one, related by voL. XVII. 
the genuine unmixed form of the complaint. It is more frequently seen where laryngitis is complicated with erysipelas or some other disease.

It appears to me, that the term SPASM is often used unwarrantably to explain the deaths of persons who have shewn symptoms of diseased larynx, and that the common notion of spasmodic asphyxia is dangerous, as it leads to the use of opiates and antispasmodics in disorders essentially inflammatory, and only to be treated with success by those who early discover and appreciate their nature and tendency. Dissection, certainly, seldom discloses in the larynx a complete obstacle to the transmission of air: this is not necessary to produce death. If the passage be gradually narrowed, so as to prevent at each inspiration the ingress of a proper quantity of air, the properties of the blood are consequently altered. The circulation of the fluid in an unhealthy state, produces a general debilitating effect : this is augmented by the fatigue resulting from the increased exertions which breathing requires. The imperfect expansion of the lungs causes in them a state of vascular congestion and consecutive serous effusion, which impedes the return of blood from the head, and gives rise to turgescence of the vessels of the brain with effusion

Mr. Costellat in the third volume of the Journal Hebdomadaire de Médecine, 1829. “Deux tumeurs existent à la place des ventricules du larynx. Elles sont formées d'une couche épaisse de pus concret combiné avec le tissu cellulaire sous-muqueux." p. 12. 
into the cerebral cavities*. "Although," says Dr. Cheyne, in his remarks on croup, " apparently the first of the vital functions which is arrested be respiration, yet this seems to arise from a want of muscular strength in consequence of failure of the sensorial power, the invariable result of defective supply of pure arterial blood in the brain." $\uparrow$ These patients, I believe; die more frequently from cerebral disorder and gradual exhaustion than from sudden or spasmodic suffocation $¥$.

Moreover, the effects of disease upon living structures are often materially modified, and occasionally

* "Si un homme n'inspire que la moitié ou le quart de l'air qui lui est nécessaire, quelque sain d'ailleurs que soit le poumon, ses vaisseaux s'engorgent."-Louis, Mémoires de l'Acad. de Chirurgie, Tom. IV. p. 456. 4 to.

+ Lib. cit. p. 33.

$\ddagger$ “ Angina laryngea præ omnibus aliis multum detrimenti affert; respirationis summum periculum adest, inde pulmones non rite expanduntur, transitus sanguinis per easdem inhibetur, sanguinis in encephalo stagnationem, et apoplexiam sequi necesse est."-Tymm, Diss. Inaug. de Bronchotomiâ et CEsophagotomiâ, § 17. Gotting. 1793.

"Sunt etiam qui apoplexia enecantur quum impedita respiratione sanguinis copia-in capite augetur. Novi etiam infantem, qui etsi recte spirabat, apoplexiam patiebatur, superorto cerebri hydrope conciliatam. Denique nonnullis debilitate mors ad ducitur, per oxygenii quidem in sanguine defectum. Qui opinantur morbum lethalem fieri, vel per tumorem membranæ pituitosæ, quæ in trachea est, ortum ab inflammatione, vel febris impetu, vel accedente pneumonia, errant, neque iis assentior. Certe exempla me fugiunt quibus id probetur."-Albers, de Tracheitide Infantum, p. 26. 
obliterated, by death. As, on the one hand, necroscopic researches frequently reveal lesions which the symptoms had not caused to be suspected; so, on the other hand, these same symptoms do not permit a doubt, that an organ is sometimes seriously diseased, although it may not appear so on dissection. Inflammatory swellings, which in the state of life are red and prominent, disappear almost entirely after death*. In watching a child, dying of erysipelas of the head and face, I was struck by the rapid disappearance of the swelling and redness. This case impressed on me the justness of the remark, that it is not right to infer that inflammation has not existed in a part, because it is found of a pale white colour on examination of the body. Andral, who states that the morbid conditions of the aerial mucous membrane are identical in its whole extent, has found it perfectly white in individuals who exhibited all the symptoms of inveterate bronchitis $\uparrow$. The failure, therefore, to discover after death a change of structure, explanatory of the previous symptoms, is not a satisfactory criterion that no such change has existed $\ddagger$. I do not, however, remember any instance, in examining the bodies of persons who have died, apparently in consequence of laryngeal, bronchial, or pulmonary disease, in which

* Bichat, Anat. Pathol. p. 8. Paris, 1825.

+ Cliniq. Méd. Tom. I. p. 175.-Précis d'Anatomie Pathologique, Tom. II. p. 464.

$\ddagger$ “In aliis etiam morbis ecce quoties post mortem omnia signa inflammationis desint, ante eam non dubia?"-Albers, de Tracheitide Infantum, p. 107. 
organic lesion was not found. Respecting laryngitis, Dr. Armstrong observes, that " respiration always grew more and more difficult, till at last death seemed literally to occur from suffocation, most probably occasioned by tumefaction within the larynx and about the epiglottis; as dissection showed that considerable inflammation had invariably existed there, without any other appearances sufficient to account for the fatal issue." *

The frequent absence of pain in chronic laryngitis is considered by Andral to be the more remarkable, as the healthy larynx is exquisitely sensible + . Inflammation of the iris may close the pupil without spasm, or the sufferer being conscious of the loss of vision \$. The changes which narrow the urethra, do not usually excite any serious symptoms in their early stage: the patient is often first alarmed by the diminution of the stream of urine. With respect to what has been denominated spasmodic stricture of the urethra, it is remarked by Mr. Lawrence $\S$, that in this case there is probably no real stricture in any part of the canal, but only an obstacle produced in some situation or other by the inflammatory tension, a partial enlargement in consequence of inflammation of some portion of the lining membrane.

* Practical Illustrations of Typhus Fever, p. 397.

+ Cliniq. Méd., Tom. II. p. 208.

$\ddagger$ See Lectures on the Diseases of the Eye, by Mr. Lawrence, Lancet, Vol. X. p. 257.

$\S$ Lectures on Surgery, Lancet, 1830. 
The phenomena of asthma have been attributed to sudden involuntary contraction of some part of the air-passages ; and that kind of difficulty of breathing, which is considered to be periodical, (although the recurrence of the paroxysms is very irregular,) has been designated spasmodic or convulsive asthma.

Whether we examine the phenomena presented during the paroxysms of asthma, or in the intervals between them, we shall in neither case find the least necessity for inferring that this disease is of a spasmodic nature. On the other hand, various circumstances concur to show, that this peculiar variety of dyspnœa results from vascular congestion of the lungs, and particularly of their mucous membrane. The increased determination of blood to the lungs may be accompanied with, and is, I believe, in many cases a consequence of, some permanent alteration in the structure of the heart or large thoracic blood vessels. This view of the pathology of asthma, and a due regard to the influence produced on the economy by that fear and agitation which are inseparable from great oppression of breathing, will enable us to account for the leading features of the disorder, both in its active and passive stage; during the former, for instance, the pallid surface of the body, the anxious and haggard countenance, the coldness of the extremities, the small, frequent, and occasionally irregular pulse; the copious flow of limpid urine*,

* An involuntary flow of urine sometimes occurs during the 
which does not begin until after the invasion of the paroxysm, and which, therefore, ought not to be said to occur "as in hysterical diseases"; the relaxation of the bowels, which have been described as acting with somewhat of the impatient hurry and imperfection of spasm; the excessive difficulty of breathing; the patient's eagerness to inhale cold air; the deficiency of respiratory sound, ascertained by auscultation; the gradual decrease of the severity of the attack; and the augmented secretion from the bronchial membrane, which marks its revolution. What better proof can be furnished of the unloading of gorged vessels, than the relief the asthmatic experiences by a spitting of blood, or by a copious mucous expectoration? In the intervals between the paroxysms patients are apt to contrast present ease with former distress, and represent that they are quite well. But in almost every case, says Dr. Forbes, there will be found, on examination, some permanent local disease of the organs of respiration, or of some other organ. Dr. Forbes likewise admits (and this admission is the more remarkable as emanating from a believer in the opinion, that the asthmatic fit con- . sists in a spasm of the muscular fibres of the bronchi,) that " diseases of the bronchi, which produce a similar contraction of the air-passages by mere swelling of the membrane, namely, bronchitis, and an affection producing nearly the same physical condition of the

paroxysms of difficult breathing, which result from the presence of a foreign body in the windpipe. See the case of a little girl, related in the twenty-seventh volume of Rust's Magazine, p. 159. 
parts from a sudden congestion of the blood-vessels, give rise to a state of respiration very like that which obtains in the asthmatic paroxysm." If we further consider that this class of patients cannot endure the slightest unusual bodily exertion or mental emotion ; that errors of diet, exposure to cold, in short any of those causes which disturb the balance of the circulation, especially such as produce irregular internal distribution of the circulating fluids, will commonly bring on a relapse; that asthma (like diseases of the arterial system, and unlike those of a spasmodic nature,) is more frequent in men than in women; that its obstinacy is proverbial ; and, finally, that, while narcotics and anti-spasmodics more frequently do harm than good, those remedies which determine blood to the surface of the body, diaphoretics, (particularly the ipecacuan,) the vapour bath, warm pediluvia, and warm diluents, are the most efficacious means of averting the attack; -we cannot but see reason to conclude, that this is neither a "pure", nor a "sympathetic", nor a "symptomatic nervous affection", but that it is essentially a disorder of the pulmonary vascular system.

Dr. Rostan, physician to the large hospital at Paris for infirm and aged women, has had peculiar opportunities of investigating this disorder, and has taken considerable pains to show that it proceeds from a surcharge of blood in the lungs. In all the dissec-

* Cyclopæedia of Practical Medicine, Art. Asthma. 
tions of asthmatic subjects made at the above institution during several years, changes of structure were observed in the large thoracic vessels, heart, or lungs *.

When a permanent lesion exists, it is difficult to explain how the symptoms should be, as they sometimes are, only occasional, the intervals of the attacks being quite free from suffering. How, for instance, a person with an aneurism pressing on the windpipe, shall experience only now and then a paroxysm of difficult breathing; or another with a tumour encroaching on the brain, shall present merely occasional indications of cerebral derangement. If, as far as the larynx is concerned, this phenomenon be explicable by spasm $t$, how are we to account for it when the brain is affected, unless by irregularity of the circulation?

The rapidity with which blood may flow to, or leave, a part of the body, and the rapid influence of the mind upon the circulating system, are both dis-

* Rostan, Traité Elémentaire de Diagnostic, \&c., Tom. I. pp. 371. 380. Paris, 1826.

+ An elderly, emaciated, and imbecile patient, who lately died, in St. Bartholomew's Hospital, of an inveterate disease of the larynx, which was discovered after death to be cancerous, was pointed out to me as being affected with spasmodic exacerbations. There were certainly periods of extraordinary distress, and others of comparative ease. The former happened previously, and the latter subsequently, to the expulsion of a load of mucus. 
played in the act of blushing, and in the erection of the penis. In the latter case we can further observe, how suddenly the magnitude of an organ may be altered by a change in the action of the bloodvessels. The momentary dizziness and obscurity of vision, produced by placing the head in a position in which the return of blood is obstructed, show how quickly important functions may be disturbed from an unusual fulness of certain vessels, and how soon restored, as the repletion subsides, without the occurrence of any change of structure.

In whatever textures inflammation occurs, we notice periods of exacerbation and remission. May not, then, the occasional aggravation of the symptoms in laryngitis be as fairly ascribed to a temporary increase of the inflammation as to an extraordinary action of the muscles of the larynx? Are the distressing paroxysms in peritonitis ever attributed to spasm of the abdominal muscles? In tetanus, or in hydrophobia, where violent spasms in the throat are remarkable, do they ever produce asphyxia? To conclude these desultory remarks on spasm, I have only to say, with the late Dr. Albers, of Bremen, "Neque adhuc vidi tracheitidem spasmodicam." *

The early symptoms of certain forms of laryngitis are liable to be mistaken for a slight cold. This error caused the death of a patient who was entrusted 
to my care. Active measures were adopted as soon as breathing became oppressed, but were insufficient to counteract the mischief, occasioned by insidious inflammation.

\section{CASE.}

Thomas Cooper, a stout florid husbandman, aged forty, was received into St. Bartholomew's in November, 1830, with an ulcer, which had arisen from an injury a twelvemonth before admission, and had laid bare the ligament of the patella: the indisposition of this part to granulate caused the protraction of his complaint. Having always lived in pure air, and been accustomed to much exercise, confinement in the hospital injured his health, and altered his appearance. He complained of having caught cold, and was hoarse. I was called to the patient one afternoon, about an hour after he had been seen by the visiting surgeon, who, like myself, had not anticipated the imminent danger. He was propped up in bed, breathing with great difficulty and with a croup-like noise, and unable to speak. The countenance expressed great anxiety, and the circulation was much disturbed, apparently in consequence of the distress of breathing. I quickly took from his arm between forty and fifty ounces of blood, which gave immediate relief, without producing faintness. Leeches and a blister over the sternum were afterwards applied. The patient was kept for several hours under the influence of tartar emetic, and then took repeated doses of calomel. He ap- 
peared to be going on favourably. But on the third night after the first suffocative attack, he suddenly fell back, while holding a cup of tea, which he was drinking, and expired in a few minutes.

The only disease discovered after death, was in the upper part of the larynx, where the increased vascularity and thickening of the internal membrane, which was slightly ulcerated just below the epiglottis, were incompatible with the maintenance of respiration. Although the symptoms in this instance were those of an acute disease, the thickened membrane possessed that firm and indurated character which is the result of slow inflammation. I therefore consider the affection to have been chronic*. The ulceration, which is often noticed in these cases after death, generally supervenes on chronic inflammation $\uparrow$.

\section{CASE.}

I lately saw an instance of odema of the glottis in a patient, thirty-nine years of age, whose husband and infant were in St. Bartholomew's hospital at the

* "L'épaississement de la membrane muqueuse est une des altérations que la bronchite chronique produit le plus souvent." -Andral, Clin. Méd. T. I. p. 183.

+ Dr. Cheyne represents that thickening of the laryngeal membrane is often followed by ulceration.-Essay on the Pathology of the Larynx, p. 178.

"Les laryngites chroniques ulcéreuses sont assez communes." -Andral, Clin. Méd. T. I. p. 180. 
same time with her, all labouring under venereal affections. She had ulceration of both tonsils, and at the angles of the mouth. While the gums were sore from taking mercury, erysipelas attacked her head and face. A tumour, which seemed disposed to suppurate, formed below the jaw ; but it disappeared under the use of leeches and poultice. As the erysipelas subsided, breathing became oppressed, but whether from cerebral disorder, or from extension of the disease of the fauces to the larynx, was doubtful. Tracheotomy was undertaken, with little expectation of success, as the patient seemed to be dying. She survived the operation half an hour. On examining the body, serous fluid was found in small quantity beneath the arachnoid membrane, in the texture of the pia mater, and in the ventricles. The brain was more vascular than natural. The soft palate, tonsils, and lining of the larynx were swollen; the latter was of a pale rose colour. The rima glottidis was much diminished by serous effusion into the membrane covering the chordæ vocales; and an appearance of ecchymosis was presented on the lingual surface of the epiglottis. Several small petechial spots, and patches of red discolouration, were observed on the internal surface of the stomach.

\section{CASE.}

Rebecca Tudor, a widowed shoebinder, aged thirtythree, was received into St. Bartholomew's on Friday morning, the 8th of April, 1831. I found her 
sitting in bed, leaning forwards, breathing with great difficulty and with a slight croaky noise, and making every now and then feeble suffocative attempts to relieve herself by coughing. The countenance was pale and approaching to lividity; the lips were covered with a dry blackish secretion; and the tongue was furred, brown, and dry. She could hardly whisper or swallow; but pointed to her throat to describe the seat of her uneasiness. The pulse was extremely low, and intermitted about every tenth stroke. The extremities were getting cold.

I afterwards ascertained that she generally enjoyed good health, and had never before been troubled with cough or difficult breathing. She had suffered, during the previous two or three months, occasional attacks of hoarseness, without pain in the throat. On the Monday before admission, whilst the catamenia were flowing, she was hoarser than usual, and swallowed difficultly. On Thursday evening, when she became much worse, a large quantity of blood was abstracted from the arm, medicine having been taken, and a blister applied in front of the larynx, without producing any remission of the symptoms. The patient considered that her complaint was aggravated by the venesection.

Dr. Latham, who had the care of the patient, decided upon the immediate employment of tracheotomy; and Mr. Earle performed the operation at ten, A.M. The relief, given by the introduction of 
the canula, was complete. She dozed shortly after the operation, and at half past three, P.M. was breathing comfortably. (Thirty minims of laudanum at night, and smaller doses occasionally when necessary.)

10th. The canula was removed last night, being obstructed by mucus. It was left out for three hours, during which time the patient enjoyed some refreshing sleep, and was then replaced, as distress of breathing returned. Deglutition is difficult and painful. (Five grains of calomel immediately, and to be repeated four hours afterwards.)

11th. She was much disturbed in the night, when the canula became clogged. I removed the instrument, with the intention of cleaning and replacing it, but as breathing was carried on easily without the tube, I determined to defer its re-introduction until the symptoms should require it. About an hour afterwards I gently separated, with two directors, the cut edges of the trachea, to make room for the expulsion of some thick mucus which interrupted breathing. This relieved her immediately. As the difficulty recurred on the directors being removed, I excised a portion of the trachea by a longitudinal semilunar incision, which afforded the same relief as when the parts were held asunder. The calomel occasioned sickness, and acted freely on the bowels. (Five grains of the blue pill night and morning.)

12th. She breathes easily, except when the arti- 
ficial opening is obstructed by mucus. A camel's hair-brush dipped in oil, with which she sweeps the course of the wound, enables her to overcome this interruption. Her voice is much improved, as well as the power of swallowing. The mercury has produced salivation with soreness of the gums. (The blue pill only in the morning, and the opiate at night continued.)

18th. The integuments beneath the chin, where the blister was placed, have been raw, inflamed, and very painful. A few leeches have been applied: yesterday the part was punctured, and a teaspoonful of thick pus was discharged. Respiration is well performed, partly through the glottis, and partly through the wound.

21st. Leeches were re-applied, as the parts continued sore and swollen. The inflammation about the wound is subdued. The pulse small and frequent; the tongue clean; bowels relaxed. (Five drops of laudanum every hour till the bowels are quieted. Broth diet, with four ounces of wine daily.)

27th. She breathes and swallows well, and speaks naturally. Air escapes through the opening only when she coughs.

May 3rd. The wound is healed, but the neighbouring parts are hard and swollen. (Six leeches and poultice to the swelling.) 
5th. The patient has had cough with impaired deglutition during the last few days, and can now only swallow fluids with difficulty. (A small blister below each angle of the jaw. Two grains of calomel with half a grain of opium every night.)

6th. Every attempt to swallow is attended with a convulsive struggle. Mucus, intermixed with blood, is now and then thrown up by an effort of retching. Nothing is discoverable on inspection of the fauces to account for these symptoms.

8th. Some yellow matter was vomited in the night. The general aspect and powers of the patient are improved, and the functions of breathing and ingestion are unimpaired.

11th. A hard inflammatory swelling is seated at the upper part of the sternum. (Twelve leeches and poultice to the swelling.)

17th. An abscess was opened at the root of the neck.

24th. The patient, being perfectly recovered, was dismissed from the hospital.

That the formation of matter in the neck, observed in this and in the preceding case, occurred in consequence of the use of mercury, I am inclined to believe, from having noticed this effect in other in- 
stances. Whether this medicine had any influence in producing the inflammatory affection of the larynx * in the former case, or whether the inflammation of this part was erysipelatous, may admit of dispute. Lisfranc $\uparrow$ states, in his commentary on oedema of the glottis, that this disease is very easily developed during the progress of phthisis laryngea, and while the system is under the influence of mercury. Mr. Lawrence has communicated to the Society the history of a patient who was supposed to have taken cold after a violent salivation. He became hoarse and affected with considerable difficulty of breathing. Bronchotomy was performed, but too late to be serviceable. By this operation Mr. Benjamin Bell gave immediate relief to, and preserved the life of, a patient who was in imminent danger of suffocation from the effects of mercury. Pelletan relates the case of a woman who suffered from chronic swelling of the laryngeal membrane, which ended fatally. She had undergone five or six courses of anti-venereal treatment; and to this circumstance Pelletan ascribes her disease $\$$.

* On the evening when this paper was read to the Society, Mr. Arnott mentioned, that he had had, within a short period, two individuals under his care, who were attacked with acute inflammation of the windpipe, while taking mercury for some chronic complaints not venereal.

† Journal Général de Médecine, par Gaultier, Tom.LXXXIII., 1823.

$\ddagger$ A System of Surgery, Vol. V.

$\S$ Clinique Chirurgicale, Tom. I. p. 19. 
MEMBRANOUS LINING OF THE LARYNX, ETC. 163

$$
\text { CASE. }
$$

I examined, at St. Bartholomew's, the body of a man, who was thirty years of age and of spare habit, and who had been treated with calomel and opium for a node on the tibia. Through negligence, he took a much larger quantity of the remedy than was ordered. Difficulty of swallowing, with hoarseness, supervened, and the pulse was then so feeble that wine and brandy were deemed requisite. For the affection of the mouth, which was not so severe as to induce an opinion that the mercury had acted prejudicially on the system, a solution of borax and honey, with tincture of myrrh, was prescribed. No marked symptoms of disturbed breathing were noticed. The patient died twenty-one days after the commencement of the mercurial treatment, and six days after its discontinuance. The larynx, and the trachea at its upper part, presented marks of inflammation of the most acute kind, with a few small ulcerations of the mucous membrane of the former, having a tawny and sloughy aspect. The inflamed membrane retained its very florid colour long after death.

A remarkable connexion is observed in the exanthemata, between the cutaneous disease and inflammation of certain parts of the mucous system. The throat, in particular, is apt to suffer in eruptive fevers. It is therefore in no wise extraordinary, that, in some cases of erysipelas, the lining membrane of this part 
should be inflamed *; and that, if this peculiar kind of spreading inflammation be allowed to proceed unchecked, it should affect the larynx and produce suffocation. Rosen observed, in Sweden, the coincidence rather than the complication of croup (laryngitis? ) with eruptive diseases. Rush frequently noticed the coincidence of croup with acute exanthematic eruptions t. Dr. Albers states, that scarlet fever is very frequently accompanied with inflammation of the larynx ; and that in smallpox and measles this organ is also apt to suffer ${ }_{\text {.. }}$. Yet, in the course of several epidemic scarlet fevers which Dr. Bretonneau had an opportunity of observing during twenty years, and some of which were so serious that a great number of patients died, it never once happened to him to see death caused by closure of the glottis from propagation of the inflammation to the larynx $\S$. Among the cases of odematous angina related by Dr. Bonillaud $\|$, is that of a sempstress, who, in consequence of over-eating, became affected with erysipelas of the face, which extended to the neck and scalp. On the fifth day the erysipelatous inflammation was much in-

* “Dans l'érysipèle de la face l'inflammation se propage quelquefois dans le pharynx et la caisse du tympan." Roche et Sanson, Nouveaux Elémens de Pathologie Medico-Chirurgicale, Tom. I. p. 269.

+ See Bricheteau's Précis Analytique, \&c. p. 344 ; and Valentin's Recherches sur le Croup.

$\ddagger$ Die Pathologie und Therapie der Kehlkopfskrankheiten, pp. 13. 57.

§ De la Diphthérite, \&c., p. 249 . Paris, 1826.

\| Archives Générales, Février, 1825. 
creased; the throat was painful, deglutition difficult, and respiration accelerated. She died in a state of asphyxia on the seventh day from the commencement of her illness. Venesection was not employed, nor were leeches applied until two hours before death. On examination, the cellular tissue of the neck and of the larynx was found to be the seat of abundant serous infiltration.

Latour twice saw inflammation of the larynx in connexion with erysipelas : he found blisters very beneficial in these cases*. Forestus $\dagger$ mentions, that he attended upon a baker, who was nearly suffocated by cynanche of the throat occurring at the same time with erysipelas of the face: but whether the larynx was the seat of inflammation in this instance is uncertain, as the treatment was judicious, and the patient recovered. Dr. Stevenson has given an abstract of some cases of erysipelas affecting the face and head, and accompanied with inflammation of the fauces. In many of these instances the disease terminated without extending further than over the soft palate, uvula, and back of the pharynx; but, " in a few it spread to the larynx, producing a state of respiration very like that of idiopathic croup." $\ddagger$

* Encyclopädisches Wörterbuch der Medicinischen Wissenschaften, Vol. II. p. 536.

+ Obs. et Cur. Med. ac Chir. opera omnia ; Lib. XV., Obs. 20.

$\ddagger$ Transactions of the Medico-Chirurgical Society of Edinburgh, Vol. II. The third volume of the same work contains 
Of seventeen cases of œdematous laryngeal angina, observed by Bayle during six years, only one ended in recovery. This intelligent physician warned the profession not to be deceived by the apparent mildness of the disease ${ }^{*}$, and recommended a prompt recourse to laryngotomy; although he appears to have possessed, at the time his memoir was published, no personal experience of the efficacy of this proceeding.

Dr. Baillie, after relating three fatal cases of inflammation of the larynx in adults, states, that the disease had a strong resemblance to croup, but is still to be considered as different from it; and that both general and topical bleeding when employed early and strenuously were of no use $t$.

Dr. Armstrong witnessed a far greater mortality in laryngitis than in any other inflammatory disease. One of his patients died in eight hours, and another in seven, from the commencement of the symptoms.

an account, by Dr. Gibson, of the Epidemic Erysipelas which appeared in Montrose in 1828. " Sometimes the internal fauces were attacked; and if it spread to the trachea, it generally proved fatal." p. 95.

* "Le peu de gravité que parait offrir la maladie chez un sujet qui se lève et qui n'a pas perdu l'appétit, ne doit pas faire illusion; l'expérience prouve d'une manière trop cruelle combien il est dangereux, dans cette circonstance, de se livrer à un espoir mal fondé." Nouveau Journal de Médecine, Janvier, 1819, p. 21.

+ The Works of Dr. Baillie, with an account of his Life, by James Wardrop, Esq., Vol. I. p. 64. 
In another case, the loss of 160 ounces of blood, within six hours, gave temporary respite to the difficulty of breathing; yet, so far from arresting the inflammation, death took place within twenty-four hours, in despite of antimonials employed towards the close *.

"Since my appointment to the Fever Hospital, I have seen", says Dr. Tweedie, " four individuals die from cynanche laryngea, two of these were convalescents from scarlet fever; and from what I observed in these cases, I am satisfied that when the larynx is attacked with acute inflammation, which generally terminates rapidly in odematous swelling of the glottis, and the subsequent death of the patient by strangulation, the only chance of saving the unfortunate sufferer is by having immediate recourse to the operation of laryngotomy. This is more especially imperative when the disease occurs in connexion with fever, because, although the cases $I$ have seen in the hospital came on during the period of convalescence, yet the powers of the patient were not sufficiently recruited to admit of the active treatment a disease so truly alarming instantly demands." $\uparrow$

Since bloodletting and other antiphlogistic and internal means, even when employed under auspicious circumstances, have generally failed to relieve that in-

* Practical Illustrations of Typhus Fever, p. 393.

+ Clinical Illustrations of Fever, p. 35. 
flammatory affection of the laryngeal membrane which is attended with interstitial effusion ${ }^{*}$; and since the few instances in which tracheotomy has been tried have been marked by signal success, it is to be hoped that the experience obtained by the loss of numerous patients, will rescue from premature death many future sufferers from this insidious and destructive disease.

\section{PART 1I.-BRONCHOTOMY.}

The obstruction of respiration by the diseases of the larynx above described, generally admits of relief by bronchotomy. In croup, where breathing is impeded by changes in the trachea and bronchial tubes, as well as in the larynx, this operation is almost invariably useless $\uparrow$. Whether it is ever advisable in cer-

* Mr. Lawrence, speaking of the treatment of phlegmonous erysipelas, observes, "I have found that venesection exerts but little influence over inflammation of the cellular texture". See his "Observations on the Nature and Treatment of Erysipelas", in the fourteenth volume of the Society's Transactions, p. 67.

+ Dr. Goelis states, after having made publicly forty-three dissections of children who died of croup,- " pseudo-membranæ sedes variæ partes tracheæ et bronchia sunt, majorem nunc, minorem eorum partem tenet, quin immo per tracheam integram et bronchia ad minimas usque ramificationes extenditur." Lib. cit. p. 84.

The seventh case related by Lobstein, in his instructive communication in the eighth volume of the Memoirs of the Medical Society of Emulation at Paris, is that of a child three years of age, whose disease was of such short duration that the production 
tain paroxysms of dyspnœa, which seem to depend upon some unusual condition of the larynx, and to arise from sympathies which we do not comprehend, appears to me very doubtful. Inexperienced in the affections described under the ambiguous terms of cerebral croup and purely spasmodic croup, I have referred to the opinions of others upon this subject, but found nothing satisfactory to guide my conduct. "In purely spasmodic croup, where there is reason to believe that no organic disease whatever had existence in the windpipe, the operation," says Mr. Porter, "might not only be resorted to at the moment of attack, but probably offers the means of re-

of false membrane was not expected. This, however, was found, on dissection, in the larynx and uppermost part of the trachea. The mucous membrane of the windpipe lower down was unaffected, and the body was healthy in all other respects. Tracheotomy might, perhaps, in this instance have proved serviceable, in conjunction with other treatment. "In unico tantum casu", says Dr. Goelis, " in quo membrana in unum punctum contracta et concentrata est, hujusque puncti sedes certissimis signis indicari potest, in transudationis stadio tracheotomia institui posset; quam rarum tamen hoc phenomenon sit, quam difficilis et ardua illius cognitio, neminem latere arbitror. In quadraginta tribus extipiciis ne semel quidem vidi, et in nullo authorum signum pathognomonicum, quo pseudo-membranæ sedes indicatur, annotatum invenio." (p. 134.) Dr. Albers proscribes, without reserve, the employment of tracheotomy in croup. He observes, " sæpius inflammationem in bronchis, quoad cartilagines habent, distinctam deprehendimus :"- " et profecto nullus, qui tracheitidem bene perspexit, aut cogitabit de tracheotomia, aut soli incisioni fidem habebit." De Tracheitide Infantum, pp. 109. 153. 
suscitation, if very speedily adopted subsequent to apparent death." The admission, that this proposal is solely supported by theory, is, perhaps, equally applicable to the remark, that "the spasm in the muscles of the glottis remains some time after death, and will effectually prevent the passage of any air." * Mr. Porter states no case to warrant a belief that spasm ever produces death by suffocation.

Dr. Albers, of Bonn, speaks of a state of disease, observable particularly in girls who are subject to irregular menstruation, in which the larynx is so irritable, that, on the slightest occasion and usually towards evening, it becomes affected with spasm, which is to be quieted by nothing, not even by musk and opium. It is attended with a drý cough, which will continue for two or three hours without interruption, and not cease until the patient falls into a swoon, or even into convulsions. "I have seen", says Dr. Albers, " these symptoms regularly repeated every evening for two months together. In this case, as also in every instance where such spasm is produced, should not tracheotomy be employed to remove this troublesome and highly dangerous condition? Particularly as this affection continues to be regularly repeated even when the menstrual functions are performed, and as the patient is liable every moment to be suffocated." +

* Lib. t. p. 52.

+ Graefe and Walther's Journal, Bd. XV. Heft 4. 
I should prefer trying the effect of some powerful revulsive agent, such as sudden immersion in cold water, a shower bath, the croton oil, or an emetic*, before proceeding to tracheotomy, which would here be less eligible than the operation advised by Desault $\uparrow$. Loss of blood by cupping on the uterine re-

* The superiority of tartar emetic and ipecacuanba over the usual remedies called antispasmodics, was noticed by Michaelis, who strongly commends the latter medicine in spasmodic affections of an hysterical character; and adds, that it seems to increase in efficacy in proportion to the nausea which it produces. De Angina Polyposa sive Membranacea. Gotting. 1778, p. 242. Dr. Albers, also, remarks, "Emetica magnam virtutem habent contra spasmum."

In acute laryngitis antimonial emetics are more efficacious than blood-letting; they are also the best internal remedy in croup. Cabanis states, that in the affections of nucous membranes emetics are generally more useful than purgatives; and that they are particularly advantageous in catarrhal inflammation of the nose, throat, or lungs. The fact is, says Cabanis, a great many more anginæ are cured by emetics than by bleeding. Cuvres Complètes, tom. II., pp. 130, 146, Paris, 1823.

Bearing in mind the obscurity which attends the development of disorders of the larynx, and their liability to be confounded, we cannot fail duly to appreciate a remedy, advisable under a variety of circumstances, generally determinate in its action, and admirable in its effects.

† " Hippocrate avoit déjà établi que dans le cas de suffocation il convient d'introduire une canule dans l'ouverture, supérieure du larynx. Ce moyen, généralement abandonné, et préconisé de nouveau, d'après une observation de Désault, ne serait proposable que dans certains cas d'affection spasmodique et passagère des muscles du larynx; et alors il faudroit que la canule, faite de gomme élastique, eut une forme et des dimensions proportionnées à l'étendue et à la figure de l'ouverture de la glotte." Sabatier, Médecine Opératoire, tom. IV., p. 89. 
gion immediately relieved an hysterical Parisian girl, who had not menstruated, and who was apparently affected with croup. The symptoms recurred, and were again subdued by the same remedy*.

The state of the larynx, which results from attempting to swallow boiling water, has been considered to require bronchotomy. From seeing a solitary case, in which this practice completely failed, I was hastily induced to esteem it of equivocal benefit; concluding that, in this accident, death was not caused by direct obstruction of respiration from the local injury, but by the general disturbance of the constitution, excited by the acute affection of a part of such exquisite sensibility and essential importance to the support of life. An account by Dr. Burgess, in the third volume of the Dublin Hospital Reports, of two cases of scalding of the mouth and throat in which bronchotomy was performed, has since assured me of the expediency of trying this mode of relief. The operation might also be of service in the case of any strong or corrosive liquid being applied to the fauces, and occasioning obstruction of the glottis.

The propriety of bronchotomy in laryngeal disease, and the prognosis of the operation, will be materially influenced by the state of the lungs, which we must endeavour to ascertain from the history of the complaint, the appearance and quantity of the expectorated matter, and by the aid of auscultation and per-

* Desruelles, Traité du Croup, p. 295. 
cussion of the chest. Previous to the operation the stethoscope is unusually profitless as a means of diagnosis. The most experienced in the use of this instrument have regretted the little advantage derivable from its application in these cases, in consequence of the diminished supply of air to the lungs, and the noise and confusion produced by each violent effort of inspiration. "It is scarcely credible how far the existence of laryngeal obstruction tends to mask all the stethoscopic phenomena, even in cases of extensive pulmonary disease."*

There are, perhaps, no symptoms that more frequently puzzle practitioners than those which seem to depend on affections of the larynx. Disease of the liver is sometimes attended with symptoms of cynanche laryngea, although no morbid appearances are presented in the larynx after death $\uparrow$.

* Remarks by Dr. Graves and Dr. Stokes; Dublin Hospital Reports, Vol. V., p. 80.

Mr. Mac Namara derived great assistance from the use of the stethoscope in the case of a boy who was much distressed by fits of cough, from a plumstone having passed into the windpipe, The Lancet, Vol. I., 1829-30, p. 78. And, in one of the cases published by Dr. Reiche, (Rust's Magazine, vol. 27,) the presence of a foreign substance in the right bronchial tube was ascertained by the aid of this instrument. The practitioner, who first treated the child, considered that it was labouring under croup; and leeches, emetics, and calomel had been employed.

+ Bonetus, Sepulchretum, Tom. I., Lib. II., Sect. I., Obs. 4.

Dr. Albers states, that liver complaints very frequently dispose to œdema of the glottis.-Die Pathologie der Kehlkopfskrankheiten, p. 106.

Mr. 
In the progress of fever and in the acute eruptive disorders of children, abscesses are sometimes formed in the neighbourhood of the glottis, which give rise to all the symptoms of croup *.

A child, eight months old, died with symptoms of cynanche laryngea, which were evidently occasioned by the pressure of an abscess in front of the thyroid cartilage, and bounding nearly the whole extent of the os hyoides. The internal lining of the air-passage was found healthy. The narrator of this case regrets, with much propriety, that the abscess-was not discovered before death $\uparrow$.

Mr. Lawrence has related the case of a young woman, under twenty years of age, who died suffocated from an aneurism behind the sternum pressing on the trachea. Her symptoms were so deceptive that it was supposed bronchotomy would be required \$.

\section{The sixth case detailed in the important Memoir}

Mr. Louis has given an interesting detail of a water-bailiff, aged twenty-three, who died suffocated in consequence of œdema of the glottis. Three large abscesses were found in the liver, and purulent formations in different parts of the body. The submucous membrane of the larynx was irregularly protuberant from serous infiltration.

Mémoire sur les abscès du foie, in the first volume of the Répertoire Général d'Anatomie, \&c.

* See the article Abscess, by Dr. Tweedie, in the Cyclopædia of Practical Medicine.

+ Edinb. Med. and Surg. Journal, No. 62, 1820.

$\ddagger$ Med. Chir. Trans. Vol. VI. p. 261. 
of Bayle, is that of an aneurismal tumour, compressing the left bronchia, and simulating odema of the glottis. "I did not," says Bayle, " see this case, but am persuaded that I should have taken the disease for cdema of the glottis."*

I know an instance where this mistake led to the performance of tracheotomy, which was attended with bursting of the aneurism into the trachea : and, from a preparation which I lately saw in the College of Surgeons, it appears probable that the same unexpected event must have annoyed another practitioner. In this preparation there is an artificial opening in the larynx; and just above the bifurcation of the trachea another opening is seen to communicate with the cavity of the ruptured sac of an aneurism.

Dr. Hope affirms, that bronchotomy has several times been performed with the view of obviating suffocation occasioned by aortic aneurism $\uparrow$.

It is unnecessary to multiply instances to prove the importance of minute diagnostic research. The obscurity in which the diseases of the larynx are often involved, and the serious errors of practice to which an ill-founded opinion may lead, should induce us to investigate with great care every disturbance of respiration, especially where the source of suffering seems to be in the larynx. Before tracheotomy is

* Nouveau Journal de Médecine, Janvier, 1819, p. 22.

+ The Cyclopædia of Practical Medicine, p. 110. 
undertaken, the actual seat of the disorder must at least be determined. The coexistence of any important pulmonary lesion will of course considerably interfere with the prospect of a favourable issue. We are not, however, to be deterred from operating either from the supposition or assurance that the lungs are simultaneously disordered with the larynx. If the cure of the disease were therefore out of the question, the operation, by lessening the frequent necessity of coughing to get rid of the increased mucous secretion, and the consequent fatigue to the lungs at a time when their unhealthy condition requires all possible repose, might yet obtain for the patient alleviation of distress and prolongation of life.

Although the opinion, that bronchotomy is too seldom performed, has been repeatedly and, I think, judiciously expressed; likewise that, when it has been undertaken, its advantages have been frequently lost by delay; the general rule has been to operate only in cases of imminent danger. Excepting in the removal of a foreign substance from the wind-pipe, the avowed object of the operator has been merely to make a way for the free passage of air, to avoid impending suffocation; without reference to the consideration, how far the operation might serve to arrest morbid action, by affording rest to the affected organ, and preventing the irritation caused by its constant exertion while in a state of disease. The advantages of performing bronchotomy very early in cynanche laryngea, and the dangers attending its delay, 
have been exposed by Mr. Lawrence. The Germans, however, claim the merit of having advised and practised the operation, in cases of chronic inflammation of the larynx, where no immediate assistance was required to preserve life *. Would not the cure of this affection be more frequent, if an artificial opening were made earlier than it has usually been, and at as great a distance as might be convenient from the diseased part $\uparrow$, so as to interrupt as little as possible the restorative process? If tracheotomy will not remove the laryngeal disease, it may facilitate breathing, and

- Gräfe and Walther's Journal, Vol. XV.p. 526.

+ An extraordinary obstacle to the successful performance of laryngotomy occurred in a case of œdema of the glottis, related by Laennec in the Memoir of Bayle. Instead of introducing the canula into the cavity of the larynx, the surgeon, who is justly celebrated for his skill and experience, passed the instrument between the thyroid cartilage and the mucous membrane, which adhered loosely to the cartilage in consequence of the disease. The advantage of selecting a healthy part to operate on, is as obvious in this instance as in the performance of amputation, or of tying an artery for aneurism. "Infra locum affectum, (says Bergier,) fieri ut plurimum queat asperæ arteriæ sectio." Richter preferred the making of the opening in the trachea at a remote distance from the larynx, to avoid injuring the isthmus of the thyroid gland, and because, as he says " inasmuch as the larynx is more impatient of irritation than the trachea, there is reason to apprehend that, when the canula is placed high up, more serious accidents will occur, than if it be placed lower down."-Anfangs-gründe, \&c. Vol. IV. $\$ 347$.

Sabatier, however, considered a wound of the middle portion of the thyroid gland to be a thing of little importance, since this lobe is nearly always very small, and it contains no considerable vessels.-Médecine Opératoire, Tom. IV.p. 87. 
thus preserve the powers of the patient until nature effects a cure, either spontaneously, or with the aid of art. It is hardly necessary to express a caution against determining precipitately on the operation, or resorting to it in the commencement of a slight attack. As in strangulated rupture, there is much more reason to apprehend improper delay, than too speedy recourse to the use of the knife.

When the symptoms of laryngitis are developed, and the inefficacy of ordinary means is evident from the daily increasing distress and weakness of the patient, from the failing voice, difficult respiration, and exhausting cough, tracheotomy should be at once performed; for if delaycd to a later period, the chance of recovery will be materially lessened, and often entirely lost. The surgeon too often waits for symptoms which threaten immediate suffocation. Yielding to the fears and objections of the sick person and his friends, or to the common notion of the vulgar respecting the danger of wounds of the windpipe; or perhaps thinking to justify the operation by showing that, under the circumstances in which it was undertaken, a doubtful remedy is better than none at all * he defers the use of the knife until extreme distress induces the dying man to submit to any mode

* “C'est par de semblables considérations que les moyens les plus salutaires sont negligés ou tout-ì-fait abandonnés. Dans un art qui a la vie des hommes pour objet, on ne scauroit imaginer combien une fausse idée peut être meurtrière." - Louis, Mém. de l'Acad. Royale de Chirurgie, Tom. IV. p. 488. 4to. 
of obtaining relief: and thus a measure, most salutary when adopted at the proper period, is brought into disrepute, because its employment is postponed till a favourable result is no longer possible.

An opinion has been entertained, that bronchotomy is " only likely to be attended with success in the more acute affections of the larynx, and is not at all advisable in cases of ulceration." * This opinion appears to me to be orroneous. Although 1 have seen no unequivocal instance of cicatrix of the laryngeal membrane, I cannot doubt that it might occur here as in other mucous membranes; and I know no reason whatever for regarding the existence of ulceration, even if its presence could be ascertained, as an objection to the operation.

The little success which has attended bronchotomy in the treatment of laryngeal diseases, must be attributed partly to its having been performed in cases to which it was inapplicable, partly to the delay of its performance, and partly to the injury inflicted by the instruments used. The operation presents nothing formidable. It has often been successfully undertaken for the purpose of extracting extraneous substances from the windpipe. In the latter cases, however, when the source of danger has been removed, the part is not irritated by the introduction of a larger foreign body.

- London Medical and Physical Journal, Vol. XLIX. p. 367. 
As a simple longitudinal incision will neither permit the easy entrance or continuance of a canula in the windpipe, nor the necessary passage of air and escape of mucus when this instrument is not used, it will generally be better to remove a portion of the trachea, and form an opening for respiration as large as the natural area of the rima glottidis : which proceeding, if properly effected, will cause no inconvenience, but afford the best assurance of the patient's safety. The surgeon may then go from the bed-side, satisfied that he has left ample space for freedom of breathing and expectoration. The injunction of a recent writer, " that no patient, on whom tracheotomy has been performed, should be left one minute for at least several days afterwards," only requires observance when an instrument, like that which this gentleman has recommended, is employed. With much more reason, I think, we may venture to establish a rule, that no person, labouring under disease of the larynx, be left by the medical attendant, unless bronchotomy has been properly performed.

In the case, related by Mr. Lawrence in the sixth volume of the Society's Transactions, of Hannah May, a young woman who underwent bronchotomy for laryngeal disease, and could not wear a canula, death appears to have taken place in consequence of the omission to remove a sufficient portion of the trachea; and in the narrative by Dr. Latham, appended to Mr. Lawrence's remarks on affections of the larynx, it appears to me that the chances of the 
patient's recovery would have been materially improved, if the irritating means employed to keep the edges of the wound asunder had been superseded by the operation of making in the first instance an ample artificial opening.

In a fatal case of angina laryngea occurring in a child five years of age, upon whom Dr. Wedemeyer of Hanover performed laryngotomy without employing a canula, the operation was attended with some unpleasant circumstances which might easily have been avoided or remedied. The crico-thyroid muscles and the fat escaped for the most part from the knife on cutting into the air-tube, so that they were not cut so freely as the larynx; and consequently they narrowed the opening of this organ during its movements. Besides, the larynx, in the acts of deglutition, inspiration, coughing, and in certain motions of the neck, was often drawn above and below the wound of the skin: thus the correspondence of the external wound with the wound of the larynx was frequently lost*.

An instance of the same accident is recorded in the Memoirs of the Academy of Surgery.

"A soldier was attacked with inflammation of the larynx, which proceeded so rapidly that on the second day he was in extreme danger. The eyes were red and protuberant, the countenance was livid, and the

* Gräfe and Walther's Journal, Vol. IX. p. 107. 
sense of suffocation so distressing that the patient was ready to tear open his throat. Blood was taken from the arm and foot at the same time; but the symptoms continued pressing, and bronchotomy was deemed necessary to save life. A longitudinal incision was made through the integuments; the sternolaryngeal muscles were then separated, and the trachea was opened transversely between two of its rings. No sooner was this done than the flow of blood into the windpipe from the small wounded vessels, excited very violent cough; and the canula could not be retained in its situation, although it was several times replaced. The patient breathed very little, or hardly at all ; for the opening of the trachea was only parallel with the external incision during certain movements. The continuance of bleeding into the canal considerably increased the danger. Perceiving the extremity to which the patient was reduced, the surgeon enlarged the wound by extending the incision of the trachea downwards. Cordials were administered, and the patient's head was bent forwards. The next day natural breathing was restored ; and in a few days the wound was cicatrized." * These cases show the necessity of making a free external incision.

Richter + rightly observes, that the greater the length of the external wound, and the more its sides 
admit of being separated, so much the easier will be the subsequent operative proceedings.

The principal danger in bronchotomy, as in the accidental wounds of the windpipe, consists in the risk of suffocation from the influx of blood into the canal. The operator should, therefore, carefully secure all bleeding vessels before he removes a portion of the trachea. If, after tying some, blood should still ooze from certain points, the application of the nitrate of silver may be useful. Hemorrhage from the thyroid veins has sometimes been so violent, during the operation, as to induce the surgeon to leave it unfinished. Such was the case in a child whom Dr. Bricheteau* saw operated on by a skilful surgeon of Paris. A similar instance is said to have presented itself to Desault; in considering which, it should not be overlooked that, in the state of impending suffocation, all the cervical veins are preternaturally distended, and that the hemorrhage is most likely to be stopped by cutting into the trachea, and removing the cause which maintains the vessels in their turgid condition.

The division of the soft parts caused so much bleeding in a child who was recently operated on at St. Bartholomew's, that the surgeon was obliged to remove the little sufferer to bed from the operating theatre without having opened the trachea, and to ef-

* Précis Analytique du Croup, p. 418, Paris, 1826. 
fect this part of the operation after waiting about half an hour for the cessation of bleeding.

Mr. Porter relates the case of a little girl, affected with croup, upon whom tracheotomy was performed. At the first incision some superficial veins were wounded, which poured out blood in fearful abundance. Some of the thyroid veins were divided, and this still added to the hemorrhage; nor was it deemed advisable to open the trachea until after the lapse of half an hour, lest the flow of blood into the windpipe should suffocate the patient*.

Scarcely had Professor Roux opened the trachea of a young woman, on whom he operated in consequence of veneral disease of the larynx, than a small quantity of blood entered the canal at the moment of inspiration. As its presence prevented the air from passing into the bronchial ramifications, the patient fell insensible. The arteries ceased to beat; a deadly paleness occupied the face; and the whole body was getting cold. Respiration was suspended, and the pulsations of the heart were no longer perceived. Far from being disconcerted by these critical circumstances, the skilful surgeon introduced an elastic tube into the trachea, and, by sucking up the blood and then cautiously inflating the lungs, succeeded in reanimating the patient. Another circumstance not less remarkable in the history of this interesting case 
is, that the operation was attended with the happiest effect, although delayed till the cerebral circulation was so seriously disturbed that the patient remained for two days afterwards in a state of unconsciousness *.

The following case is instructive in more than one respect.

\section{CASE.}

A healthy youth contracted, in the summer of 1830, a venereal complaint, which was imperfectly treated. He was subsequently attacked with pain in the throat, difficult deglutition, hoarseness, and ultimately loss of voice. In the beginning of December the soft palate and uvula were ulcerated, and the tonsils swollen. The patient was at this time suspected to have also ulceration of the larynx. Fumigations of the deuto-chlorate of mercury were employed. After the first fumigation he felt a pricking sensation in the larynx with dryness of the throat. The remedy was nevertheless continued. Fortyeight hours after the first fumigation, dyspnoea and all the symptoms of œdema of the glottis supervened. The patient had been in danger of suffocation fourand-twenty hours when Mr. Roux first saw him; but during his visit no serious symptoms threatened. On the next day, December 14th, the breathing was extremely difficult; and, as the pulse was strong and

* Andral, Clinique Médicale, Tom. II. p. 215. 
frequent, venesection was performed. A quarter of an hour afterwards Mr. Roux proceeded to laryngotomy. He had scarcely divided the crico-thyroid membrane before some efforts of expiration were made, and frothy blood was expelled. Suddenly respiration and the action of the heart were suspended; and the patient died, evidently suffocated by the flow of blood into the air passage.

Dissection.-The epiglottis had twice its ordinary thickness, with slight ulceration at its borders, and numerous small vascular growths on its surface. The glottis was œdematous. The membrane of the right vocal cords was ulcerated. The lungs were gorged with blood, and like those of a person suffocated *.

The embarrassment Desault experienced from hemorrhage on the occasion alluded to, led him to decry bronchotomy as an "opération toujours facheuse," and to recommend, in cases requiring an artificial admission of air into the lungs, the irritating and troublesome process of introducing an elastic tube through the nostril into the trachea $\uparrow$.

* Archives Générales de Médicine, Dec. 1831.

+ To the many forcible objections adduced by Mr. Porter against the practice of Desault may be added that of the necessity of frequently removing the tube to clear it of the accumulation of mucus, which no efforts of the patient can expel. Even in the much shorter and wider tube which has been used after tracheotomy, this inconvenience has been found to be considerable. 
Dr. Cheyne, from an excessive fear of bleeding, has advocated an operation equally reprehensible, namely, that of introducing into the trachea a trocar and canula without any previous incision. "By this means," says Dr. Cheyne, " the hemorrhage, which is productive of such dreadful embarrassment and danger, will be avoided, the operation will be more expeditiously done, and part of the horror of the scene will be avoided." * The reflexion that the canula must irritate by being moved up and down with the larynx, which does not move in association with the skin, combined with the danger of wounding a large blood-vessel irregular in its course $\uparrow$, the œsophagus, or contiguous important parts, and the depth it may be necessary to penetrate in consequence of unusual distance of the trachea from the surface, ought to preclude this use of the trocar. Were tracheotomy required in early life, the comparatively small size of the windpipe at this period would increase the difficulty. And when we read that in one instance a surgeon, who essayed the operation, was obliged to give it up, as he absolutely could not find

* On the Pathology of the Larynx, p. 173.

+ Two plates are given in Neubauer's Opera Anatomica Collecta, (Frft. and Lips. 1786,) in which arteries of considerable size are represented ascending perpendicularly in front of the trachea; and various references are made to other unusual distributions, which ought not to be lost sight of in the performance of tracheotomy. See also Meckel's Handbuch der Menschlichen Anatomie (Vol. III. p. 152) for an account of irregular conformation of some cervical vessels which are exposed to injury in tracheotomy. 
the trachea! - and that in another instance the carotid artery was wounded, what can we expect to result from this rude proceeding of stabbing the throat?

So far was Casserius from regarding with horror the wound required in bronchotomy, that he attributed to the bleeding thus produced a salutary influence over the disease*. In the case of angina laryngea, the operation, says Richter $\uparrow$, not only removes the most pressing symptom, the difficulty of breathing, and the danger of suffocation, but by the local bleeding which it occasions, greatly contributes to the complete cessation of the inflammatory action. It has been several times observed that the patient has obtained relief as soon as the integuments were divided, and that an hour after the operation he has been able to breathe through the mouth.

As the parts in front of the trachea vary so much in thickness in different persons, and at different times in the same individual, it is expedient to have canulæ of different lengths $\ddagger^{\dagger}$. It is the depth of the trachea,

* “A cujus vulnere, imo et subsequente hæmorrhagiâ (licet parvâ nec pertimescendâ) operatione portenditur securitas, ægritudini cita curatio."-Casserius de Vocis auditusque Organis. Historia Anatomica, Lib. I. cap. 20. fol. Venet. 1609.

+ Anfangs-gründe der Wundarznegkunst, Vol. IV. § 331 .

$\ddagger$ “ Interim præstaret semper habere tubulos variæ longitudinis, cum quandoque major requiratur tubus, dum partes dissectæ tumentes, postea facerent ut non sufficeret brevior tubus."-Bourlart de Bronchotomia; Collectio Diss. Med. Lovaniensi, Tom. II. p. 177. 
which from dissecting the dead body we are not led to expect, that makes the operation extremely difficult in some cases. The trachea of a person labouring under laryngitis was laid bare at full an inch from the surface. "Those", says Dr. Johnson*, "who talk about cutting out a piece of a tracheal ring at the bottom of such a cavity as this, while the trachea itself is in constant motion, and the surrounding muscles ever altering their relative positions in the efforts at respiration, have probably never practised it." In a patient suffering from œdema of the larynx, on whom Mr. M'Namara operated, the trachea was two inches and a half below the surface, to such an extent had serous infiltration of the neck proceeded $\uparrow$. The neck of a labourer, who underwent tracheotomy for cynanche laryngea, was the seat of emphysema. The knife penetrated to the depth of more than an inch and a half before the trachea was exposed; and then it was almost impossible to fix the tube so as to permit the excision of a portion of it $\ddagger$.

"I have lately," says Mr. Lizars, " seen three cases of cynanche laryngea in adults, where the muscles on the anterior part of the neck were infiltrated with pus." \$

* Med. Chir. Journal, Dec. 1820.

+ 'The Lancet, 1830-31. Vol. I. p. 269.

$\ddagger$ Case by Mr. Porter, in the fifth volume of the Dublin Hospital Reports.

$\S$ A System of Anatomical Plates, Part IX. p. 26. 
Frederick Dekkers's ingenious proposal to introduce a canula into the trachea by means of a trocar, after the preliminary incision of the soft parts, was duly eulogized by that accomplished surgeon, Mr. Louis, who reprobated the advice subsequently given by Dionis ", and approved by Dr. Cheyne. "The idea of Dekkers," says Mr. Louis, "is exceedingly happy. It simplifies the operation, facilitates its execution, and renders it exempt from all inconvenience. The termination of the history of the art will render this truth more striking." +

\section{With a slight modification of Dekkers's instrument,}

- “ Du temps de Dionis, il étoit possible de mieux dire: il auroit dû etre plus instruit et donner de meilleurs préceptes rélativement aux perfections acquises."-Louis, Mém. de l'Acad. Royale de Chirurgie. Tom. IV. p. 496. 4to.

+ The editor of the Journal de Médecine has expressed an equally favourable opinion of Dekkers's operation. “Ce procédé a été modifié diversement par Dionis, Garengeot, Ledran, Bauchot, et autres opérateurs, mais il survivra à toutes ces innovations."-Tom. LXXIV. p. 370. 1821.

The question "An Tracheotomiæ nunc scalpellum nunc trigonus mucro?" is discussed by Bergier in the second volume of Haller's Disputationes Chirurgicæ. The author concludes his discourse in the following words :- " Sunt etiam qui trigoni mucronis usum omnino reprobent; dum enim, inquiunt, magna vi in tracheam mobilem facileque vacillantem adigitur, periculum est, ne aut deviet instrumentum satis crassum, aut posterior cum anteriore lredatur tracheæ paries. Id vero non timuit peritissimus Heisterus; reque ipsâ nullum hujusmodi periculum imminet, modo ne obtusâ acie, aut rudis chirurgi manu, operatio instituatur. Ergo tracheotomiæ nunc scalpellum nunc trigonus mucro." 
his mode of operating might, perhaps, in some cases be renewed with advantage. This plan is calculated to obviate the danger of hæmorrhage into the airpassage, and the vexatious and mischievous delay it may cause. Besides, it enables the operator to accomplish his purpose without the assistance of another person. The proposed alteration consists in substituting a curved silver tube for the straight canula, and in having part of the shaft of the trocar formed of conjoined links. Or a sharp pointed knife may be so constructed and fixed to a steel shaft of three or more moveable joints, as to permit the blade to assume the curved form of the canula, and to pass through it easily*. The former appears to me to be the better instrument: the latter might be employed by those who prefer making a simple longitudinal incision of the trachea to a triangular perforation.

The practice of removing a slip. of the trachea, recommended by Mr. Lawrence when the canula causes inconvenience, has seemed to me to deserve a more general adoption. I was happy to find my views on this subject corroborated by several respectable authorities.

“After the operation of laryngotomy or tra-

* There is annexed to this paper a lithographic print of the two instruments which were made for me by Mr. Ferguson, surgical instrument maker to St. Bartholomew's Hospital : by which means the reader will have a clearer idea of them than by any verbal description I am able to give. 
cheotomy, nó person," says Walther, " would think of introducing a pledget into the wound of the windpipe; but a proceeding similar to this, and equally injurious, is generally recommended; I mean the introduction of a canula through which the patient shall breathe, when the operation has been performed, not for the extraction of a foreign body which has entered the air-tube, but on account of interrupted respiration through the rima glottidis. Much trouble has been taken to find out the most suitable form, length, and mode of fastening of such an instrument. But its presence in the wound must operate very prejudicially. It causes violent irritation of the mucous membrane of the air-passage, and spasmodic cough, and increases the danger of inflammation and of its terminating fatally. When a small foreign body has passed into the windpipe, we recognize plainly and determinately the necessity of removing it immediately; and shall we not scruple in the opposite case to introduce purposely a much greater foreign body, which must be far more injurious? The introduction of the canula is unnecessary for the security of freedom of breathing. The patient may breathe very well through the wound, if it be made sufficiently large, and kept open by a suitable apparatus and position of the head."*

Dr. Albers $\uparrow$ likewise insists upon the rejection of

* Gräfe and Walther's Journal, Vol. IX., p. 204.

+ Ibid. Vol. XV., p. 537. 
every kind of canula as well as those recommended by Bell and Richter; as these instruments irritate and give rise to accidents which destroy the object of the operation.

Mr. Carmichael * prefers the removal of a piece of the trachea to the introduction of a canula, because the latter is not only a source of great distress, but is by no means equal to the other for allowing the easy exit of mucus. And Pelletan, whose precepts are generally founded on ample experience, advises that the wound of the trachea should embrace several of its cartilaginous rings, as no inconvenience attends this mode of operating, which secures a free passage for respiration and the excretion of mucus, at the same time that it dispenses with the use of the canula, which would only add to the irritation, even if the patient could endure it $\psi$.

Whether the incision include a line or two more or less of cartilage, so long as the opening is made sufficiently large, is a matter of little importance, either as regards the pain or trouble of the operation, or the future closure of the wound.

Perhaps the only reason which authorizes the introduction of the canula, is, that it prevents the flow of blood into the trachea at a time when any addi-

* Trans. of King and Queen's Colleges, Dublin, Vol. III., p. 175.

+ Clinique Chirurgicale, Tom. I. p. 31.

VOL. XVII. 
tional impediment to breathing might immediately prove fatal. The disadvantages attending its use are so great, that it should be employed as little as possible. So long as the wound bleeds, a metallic or an elastic tube may be useful. But when bleeding has ceased, and the retraction of the soft parts prevents them from obstructing the opening in the trachea, persistance in the use of an artificial tube is unnecessary and injurious. The irritation which the instrument causes, is aggravated by withdrawing and replacing it when obstructed by a concretion of mucus. Besides, the extraneous body must, by irritating the internal membrane, increase that secretion, from an accumulation of which the principal danger is to be apprehended. If the mucous secretion is excessive, and the laryngeal disease prevents its expulsion, suffocation will be as inevitable as though the rima glottidis were hermetically sealed.

The membrane of the windpipe above the wound becomes gradually thickened by the irritation of the canula. This alteration of structure may either obliterate the cavity of the larynx, destroy speech, and render the abandonment of the instrument impracticable, or so far diminish its capacity as to augment the difficulty of speaking, and the danger of closing the wound.

In the Anatomical Museum of St. Bartholomew's are the larynx and trachea of a man who underwent bronchotomy, and wore a tube for several years, till 
he died of extensive disease of the lungs. The orifice in the trachea is immediately below the cricoid cartilage. The rima glottidis is much narrowed by thickening of the membrane covering the chordæ vocales. How far the use of the canula may have tended to produce or increase the alteration observed in the larynx, or the pulmonary affection, it is not in my power to determine. Mr. Stanley informed me that the operation gave immediate relief, and that he considered the morbid appearance in the larynx to be the effect of the original disease which had obliged him to operate.

PART III.-WOUNDS OF THE THROAT.

Wounds of the throat deserve to be considered among the causes which give rise to inflammation with swelling and thickening of the laryngeal membrane. The following history is presented to show the necessity of not overlooking, in the treatment of these injuries, the disposition to slow change of struc. ture in the membrane.

\section{CASE.}

Thomas Tibbett, aged fourteen, having been detected in thieving, and roughly treated, cut his throat with a razor on the last day of January, 1831, and was immediately brought to St. Bartholomew's. There was a gaping transverse wound of the integuments about two inches in length. The windpipe 
was wounded in two places; one incision having been made through the upper part of the thyroid cartilage, and the other through the crico-thyroid membrane. He had lost very little blood, and no vessels required to be tied. The parts were approximated by keeping the head bent forwards, and no attempt was made to unite any part of the wound by ligature. As fluids; which he attempted to swallow, came freely out of the wound, inducing an opinion that the pharynx was injured *, and as deglutition excited cough, and was attended with the inconvenience of separating the severed cartilages, he was fed with milk by the aid of an elastic tube, passed through the nostril: to this operation he quietly submitted, as it was less troublesome than swallowing, and his appetite was keen. At first there was much frothy mucous discharge from the wound, with noisy and sibilant breathing; but the patient suffered little. On the 20th of February he still breathed through the opening, but did not require to be fed, and was able to walk about in the ward. When the prospect of recovery was most favourable, difficulty of breathing supervened. The upper wound of the larynx, which was much the larger one, being sufficient to allow a free entrance of air, the obstruction was considered to be caused by

* That the escape of fluids through a wounded windpipe, during deglutition, is no sure criterion of a breach of structure of the gullet, is proved by two cases of self-murder recorded in the twelfth volume of the Lancet, and by the occasional occurrence of this symptom after the performance of bronchotomy for disease of the larynx. 
inflammation lower down in the windpipe, and leeches were accordingly applied. He died on the 27th of February.

The following appearances were found on dissection.

The lateral borders of the epiglottis were approximated; the membrane covering it and the neighbouring parts was swollen, and the glottis much contracted. The upper wound of the larynx would just admit a large bougie. Its communication with the pharynx was nearly obliterated by cicatrization. The lower wound was healed, and scarcely recognizable externally, but clearly indicated within by a wrinkled and indented appearance of the lining membrane. Between the two wounds the chordæ vocales were involved in a fleshy swelling (épaississement par hypertrophie), through which a female catheter passed without difficulty. The tracheal membrane was rather more vascular than usual. There were extensive old adhesions of each pleura, with depositions of gritty and cheesy matter in the lungs and bronchial glands.

This poor boy's life might have been prolonged, had a tube been opportunely introduced through the wound, so as to traverse the seat of obstruction. Tracheotomy, though less eligible, would likewise have effected the purpose. When the larynx is obstructed by the inflammation and swelling which su- 
pervene on wounds of this part, Richter * recommends either the placing an artificial tube in the existing aperture, or the performance of tracheotomy. By the latter operation Habicot $\uparrow$ saved from suffocation a youth who had a cut of the throat involving the pharynx.

The perusal of single cases of any disease is generally found unsatisfactory; the reader being deprived of the advantage of comparison and induction. . Besides, in surgical practice, it is only from an assemblage of undisputed individual histories that general conclusions should be formed. I therefore take the liberty of introducing a few examples, (giving merely an abridgment of the original narrations,) the interest of which appears to me to be increased by connexion with the above account. The first two cases serve to illustrate the acute form of inflammation previously described; and they are the only instances of the kind on record that I am acquainted with. The rest are more analogous to the foregoing history of Tibbett.

\section{$C A S E+$.}

A workman, aged thirty-six, pursued for debt, and

* Lib. cit. $\oint 333$.

+ Question Chirurgicale, par laquelle il est démonstré que le chirurgien doit assurément practiquer l'opération de la Bronchotomie, vulgairement dicte Laryngotomie, ou perforation de la fluste ou tuyau du poumon.-Paris, 1620.

$\ddagger$ This and the next case are translated from the eighth vo- 
resolved to finish a life of trouble, cut his throat with a razor between the os hyoides and thyroid cartilage, and was conveyed to the hospital at Toulon on the 30th of December, 1819, four hours after the accident. The lips of the wound were brought together by adhesive straps, and a compress was applied : but ere long hemorrhage ensued, and it was necessary to tie three small arteries. The wound was again dressed, and the head inclined towards the chest. The next day the pulse was excited, but there was no other unfavourable symptom. Blood was taken from the arm, and soothing drinks were prescribed. On the fifth day alarming symptoms suddenly appeared ; fits of imminent suffocation, agitation, heat of skin, paleness of the face, tumefaction of the neck, complete loss of voice, hissing and very laborious inspiration, and less difficult expiration. A large bleeding was practised from the arm; fifteen leeches were applied on the neck, and sinapisms on the feet : but the paroxysms increased, and the patient died in the evening.

Examination. - The upper part of the thyroid cartilage had been cut, and the hyo-thyroid membrane divided. There was considerable ecchymosis of the fold of membrane which unites the epiglottis to the arytænoid cartilage of the right side. The membrane of the epiglottis, and of the upper part of the larynx and its ventricles, was odematous. The serosity was lume of the Recueil de Mémoires de Médecine, de Chirurgie et de Pharmacie Militaires. 
easily expressed from the swollen membrane. The lungs were the seat of a slight sanguineous infiltration.

\section{CASE.}

A Swiss soldier made with a knife a triangular wound of his throat, about two inches long, at the upper border of the thyroid cartilage. He was immediately taken to the military hospital at Toulon. There was scarcely any bleeding : the wound was therefore at once dressed with strips of adhesive plaster, and covered with charpie and compresses, which were confined by a circular bandage. The patient was instructed to keep his head bent forwards. In four hours hemorrhage took place. When the dressings were removed, the blood flowed freely, but the bleeding orifices could not be found. A piece of agaric was applied, and the wound dressed (or rather smothered) as before. After an hour the charpie was again soaked in blood; but, as this did not trickle down the neck, the dressings were not disturbed.

A soft blueish swelling now formed at the base of the jaw on the left side. His breathing became very difficult, and the face injected; suffocation menaced; he frequently raised his hands to tear away the dressings. As the bandage seemed too tight, an ordinary chin-cloth was substituted. The wound ceased to bleed, and the patient felt relieved; but he continued restless and agitated, and often assumed 
the sitting posture, which seemed to give him ease. The difficulty of breathing soon increased; and he died six or seven hours after his entry into the hospital.

Examination.-The course of the wound was occupied by clots of blood, which had accumulated in the situation of the swelling observed during life. All the cellular tissue of the anterior cervical region was infiltrated with blood, which had come principally from a wound of the laryngeal branch of the right superior thyroid artery. There was considerable œdema of the membrane investing the arytænoid cartilages ; and the chink of the glottis was nearly obliterated by the swelling. The veins of the encephalon were more distended than natural; and the lungs were congested.

\section{$C A S E *$.}

A young woman, who had divided the larynx just beneath the thyroid cartilage, went on well till the fourth week, when difficulty of breathing came on, and increased during twenty-four hours till death. The cavity of the windpipe above the wound was filled up by "granulations of flesh" + : and when the external

* Wilmer's Observations in Surgery, London, 1779.

+ Excrescences, resembling granulations, are often observed in irritated and inflamed mucous membranes. I have seen them of considerable magnitude in a youth's bladder, which had contained a rough calculus. In Egypt, where ophthalmia has so 


\section{opening became so small that the lungs could not be supplied with air from that source, a difficulty of}

much prevailed, Larrey found pterygium a very common affection, as well as a granular state of the conjunctiva. (Clin. Chirurg. T. I. p. 394.) Morgagni has the history of a man who died suffocated soon after symptoms of affection of the throat were noticed. On examining the larynx, its internal surface presented reddish protuberances, which were like " inflammata condylomata," but consisted of the mucous membrane and its glands swollen from increased vascularity and interstitial serous effusion. (De Sed. et Caus. Morb.) When hypertrophy of the membrane of the windpipe is confined to a circumscribed point, it may give rise to tumours which project more or less considerably above the level of the rest of the mucous lining: these have a large base, and are more conmon in the larynx than in other parts of the air-tube. Andral mentions another form of hypertrophy, which affects the mucous follicles, and causes a peculiar granulated appearance of the laryngeal membrane. Warts, and growths like certain syphilitic cauliflower excrescences, are sometimes met with in the larynx. There are three specimens of this kind in the Museum at Guy's Hospital, and a very fine one in the Hunterian collection. Dr. Albers has described, under the title of Polypus of the Larynx, tumours which were firm and fleshy. Two such cases were seen by Desault, and a third is mentioned in his works. In all three the tumour was pyriform, with its pedicle inserted into one of the ventricles. Pelletan tells us of a man who was suddenly suffocated by a firm and undulating tumour of the size and shape of a small nut, blocking up the air-passage. It was attached in the neighbourhood of the glottis by a longish pedicle. A similar case was seen by Dupuytren. The patient was subject to fits of dyspnœa, for which no cause could be assigned, and during one of them he suddenly died. Unfortunately, when such tumours are formed within the larynx, we can only ascertain their existence by dissection. The patient might easily be completely relieved, were the cause of his symptoms recognisable during life. 
breathing commenced, and at length the patient was suffocated by the very efforts which nature made to heal the divided parts.

\section{$C A S E *$.}

A young Savoyard had his throat cut transversely with a knife by a comrade who attempted to rob him. The trachea and oesophagus were wounded. The progress towards recovery was remarkably favourable.

In fifteen days the false passage of fluids in swallowing had ceased; and in six weeks the whole wound was cicatrized. When considered cured, but still kept in the hospital, he was visited in bed by a commissary, who came to confront him with his assassin. The lad arose with promptitude and emotion, and fell dead at three steps from his bed. The examination of the body disclosed a remarkable contraction with swelling of the mucous membrane opposite to the cicatrized wound of the trachea. The cicatrix of the œsophagus was confounded with that of the surrounding parts. No other internal lesion was discovered.

Sir Charles Bell relates the case of a little girl on whom he operated to extract a plum-stone from her windpipe. For some time after the operation he was very anxious for the child's life. The reason of this anxiety was founded on the following circumstances.

* Pelletan, lib. cit. p. 38. 
A woman, in phrensy, plunged a penknife into her throat. It pierced the thyroid cartilage at the union of the chordæ vocales. She was suffocated at the end of some months by the granulations which filled up the passage of the glottis.

Another woman drew a penknife down her neck, and divided five rings of the trachea. She survived the first effects of this wound, but was suffocated by the retraction of the cut edges of the cartilages, and the swelling of the inner membrane, which diminished the capacity of the tube. These instances of death by suffocation reminded the author of the necessity of performing bronchotomy on some of those who have cut their throats, as well as in some cases where suicide has been attempted by firing a pistol into the mouth *.

A patient, suffering from laryngitis, underwent laryngotomy in the Glasgow Royal Infirmary on the 6th of March, 1828. The disease had to all appearances subsided, and the wound healed. On the 30th rigors and violent orthopnœa came on suddenly. Immediate relief was afforded by opening the cicatrix of the former wound. He was dismissed from the hospital quite recovered on the 4th of Junet.

* Surgical Observations, Part I. p. 44. See also a Clinical Lecture by Sir C. Bell, on the performance of Laryngotomy, in the fifth volume of the London Medical Gazette, 1829-30.

+ London Medical and Surgical Journal, December, 1828. 
In the Medico-Chirurgical Review, (July 1831,) a remarkable case is related of a wound of the trachea, followed by closure of the larynx and aerial fistula. Breathing became difficult as the external wound healed; and the unhappy man at length suffered so much, that he pushed a knife through the cicatrix. Dyspnœa recurred as the wound again healed. The patient, therefore, constructed and introduced a leaden tube, which enabled him to breathe easily. He died six years afterwards of phthisis, after experiencing repeated attacks of bronchitis. The obliteration of the air-passage was found, on dissection, to be complete where the trachea joins the larynx.

Professor Lüders has published an account of a suicidal attempt, in which the trachea and esophagus were cut through. Difficulty of breathing was produced as the opening in the trachea became narrowed by granulations: these were at first pushed aside, and kept down by caustic: but to prevent suffocation, it was at length necessary to introduce an artificial tube, which the patient continued to wear when seen two years afterwards*.

in the case of a young woman who had divided the crico-thyroid ligament, in attempting suicide, and had afterwards worn a silver canula through the wound, Mr. Liston was enabled, by gradual dilatation of the glottis by bougies and elastic tubes, to restore it from a nearly complete state of obliteration

* Gräfe and Walther's Journal, Vol. XIII. 
to its normal diameter, and eventually to close the wound, and re-establish natural breathing. The patient also slowly recovered her voice*. The treatment adopted by this ingenious surgeon was attended with serious inconveniences and considerable danger; but the remarkable success which he obtained, justified the proceedings, and proves how much may be done in these cases by skilful management.

In some of the cases above cited, as well as in that of Tibbett, life might have been prolonged by surgical interference; and the unfavourable termination may be ascribed, in a considerable measure, to the circumstance of the wound being so near to the chordæ vocales. When the membrane investing these ligaments is long irritated, it is gradually consolidated and thickened. If the irritation be great and sudden, a more rapid inflammatory swelling speedily causes suffocation. The disposition to these changes of structure deserves consideration, in estimating the comparative merits of tracheotomy and laryngotomy. The case of the Savoyard, and one quoted from Sir Charles Bell, show that, even in a part of the windpipe least liable to such swelling of the internal membrane as shall intercept the passage of air, this accident may still destroy life.

As no observations on wounds of the throat have appeared in the Transactions of the Society; and as these alarming accidents occur frequently, and some

* Edinburgh Medical and Surgical Journal, January, 1828. 
difference of opinion exists respecting the best mode of treating them, the present may not be deemed an improper occasion to invite attention to the experience of Dr. Rust on this subject. The three following cases are recorded in his monograph on wounds of the windpipe and gullet, published at Vienna in $1815^{*}$; and they are here cited, not so much for the sake of the cases themselves, as for the reflections with which the author concludes them, and which I shall set down in his own words.

\section{$C A S E$.}

A servant, aged twenty-one, of weak constitution, was induced, through the treacherous conduct of her lover, who had already made her a mother, in despair and weariness of life, to adopt the culpable resolution of destroying herself. On the eve of the 1st of January, 1815, this broken-hearted girl retired to bed provided with a razor; and when all was quiet, and the light extinguished, she proceeded to perpetrate her intention. A fellow-servant, who slept in the same room, was first aroused about four o'clock in the morning by her noisy rattling breathing. When a light was brought, and the master of the house came to assist, she was insensible, and deluged in blood. The surgeon, who was called in, finding the windpipe completely cut through, de-

* Beobachtungen über die Wunden der Luft-und Speiseröhre, Wien, 1815. 
clared that she could not live, and sent her to the Vienna General Hospitak, where Dr. Rust saw her at nine a. $\mathrm{m}$.

The whole surface of the body was death-like pale, and the countenance had all the aspect of a dying person. The brow was covered with cold sweat, and the eyes had lost their lustre. The extremities were cold and pulseless; and the existence of life could only be inferred from the indistinct action of the heart, the occasional murmuring respiratory efforts, and the more frequent convulsive movements. The wide gaping wound, gorged with clotted blood, penetrated between the thyroid and cricoid cartilages, and through the anterior wall of the pharynx; so that when the coagulum was removed, the finger could be introduced into the œesophagus. The severed windpipe was drawn considerably downwards, and was apparent only during the coughing, produced by the examination of the wound. The divided vessels had retracted, and the bleeding almost entirely ceased.

After the cut surfaces of the windpipe were united by. a single loop, and those of the integuments by the interrupted suture, the head was bandaged, and inclined forwards; and the limbs were rubbed, and enveloped in hot cloths. The patient soon began to revive : respiration became more regular : warmth and pulsation returned in the extremities, but with them hemorrhage from the wound, and threatening suffo- 
cative cough. The bandage and sutures were immediately removed, and two blood-vessels tied. Fainting was re-produced, from which she soon recovered, when the parts were adjusted as before. 'lo prevent the recurrence of hemorrhage, cold damp cloths were applied on the throat. After a few hours, perfect consciousness was restored, and every thing appeared favourable. She now attempted to tear off the bandages, and to finish her suicidal design; but through the persuasion of Dr. Rust, and the interposition of a priest, she was conducted to a knowledge of her duty sooner than was expected.

Jan. 2d. The pulse small and feeble ; respiration tolerably easy. She suffered from excessive thirst, which she could not appease, as every attempt to drink produced violent cough. Evacuations were procured by clysters; and the large intestine was replenished by injections of meat-broth with yolk of eggs. The thirst was diminished by the use of a warm bath.

4th. Respiration hurried; the pulse excited ; pain in the wound and windpipe ; oppression of the chest, and slight dry cough. $A$ blister was applied on the nape, and twelve grains of calomel were taken in divided doses. Instead of the cold cloths, warm fomentations were employed. The clysters were continued. Towards evening menstruation appeared.

5th. A remarkable remission of all the symptoms. vol. XVIr. 
The calomel was repeated, and a little mucilaginous drink was swallowed without much trouble, when she attempted a very small quantity each time. A greedy effort was immediately followed by cough and escape of the liquid through the wound.

6th. Symptoms of salivation appeared. As the bowels were confined, an injection of senna and Epsom-salt was administered with good effect.

7th. Nutritious clysters were used; no medicine was taken.

8th. All the feverish symptoms returned with increased violence, and troublesome dry cough. The pulse was small, but had a peculiar hardness. Notwithstanding the previous hemorrhage, and the menstruation which had just ended, Dr. Rust directed the loss of eight ounces of blood from the arm, which gave immediate relief. An oily emulsion, with a small quantity of the extract of henbane, was also ordered.

9th. The fever was moderated, and the salivation less. A blister was placed between the shoulders. The costive state of the bowels was relieved by a strong purgative injection. The emulsion was continued; and, as the patient daily swallowed better, she was principally nourished with thin broth taken by the mouth. Dr. Rust now removed the sutures, and the noose that united the larynx, but kept the head fixed forwards. 
11th. She was again feverish, coughed incessantly, and despaired of recovery. Six leeches were applied in front of the larynx : the bowels were freely acted upon, and the dose of hyoscyamus was increased : but no marked relief followed.

13th. Fluctuation was perceptible beneath the united skin wound : this was opened : a quantity of purulent matter, with mucus, escaped; and the alarming symptoms at once disappeared.

14th. When taking her broth, some of it still came through the opening : her strength was considerably improved : it was consequently determined to introduce nourishment for a few days solely by clysters. This had so good an effect, that on the seventeenth the wound was again cicatrized.

At the end of January the patient could swallow well ; but she had hectic fever, with cough and puriform expectoration.- These symptoms were removed by the insertion of two issues in the upper arms, and the use of digitalis, Dover's powder, bark, \&c.

She left the hospital on the 20th of March, being hoarse, but in all other respects well.

\section{CASE.}

J. A. a distressed tradesman, forty years of age, cut his throat with a pocket-knife on the 12th of 
April, 1814. The wound, three inches long, penetrated through the larynx and corresponding anterior part of the alimentary tube, dividing the thyroid cartilage obliquely from its left upper cornu towards the right lower cornu. When brought to the hospital he was considered dead, and no measures were adopted. Three hours afterwards Dr. Rust found the man cold, and apparently lifeless; yet he deemed it his duty to unite the wound by sutures, and fix the head in a proper position. In less than half an hour the supposed deceased began to breathe. Some cordial drink was administered; but the greater part of it escaped through the wound, and violent cough was excited. The next day the patient was greatly recovered, but he could not swallow. He was afterwards much oppressed, and occasionally experienced a suffocative fit. Nutritious fluids were injected into the lower bowel, and baths were used to mitigate his thirst. Notwithstanding he had lost much blood, Dr. Rust was twice obliged to order venesection and leeches, to subdue the inflammatory disturbance. Large doses of calomel alone, and afterwards in conjunction with the extract of hyoscyamus, small doses of camphor, and lastly the cinchona, contributed to the patient's recovery. In this instance, also, a mucopurulent formation took place beneath the cicatrized integuments; but it opened without surgical assistance, and left a sloughy ulceration, which soon improved under simple treatment. On the 19th of May the ulcer was still open, but the patient was so far restored, that he deceived the attendants, and 
MR. WOOD ON WOUNDS OF THE THROAT. 213

escaped over the high hospital wall. He was brought back on the same day, and remained in the hospital until the 29th of May, when, being completely recovered, he again absconded to avoid the police.

\section{$C A S E$}

A. K. a joiner, 25 years of age, had a fit of insanity on the 8th of February, 1814, according to his own expression, on account of vexations with his fellow-workman, and thwarted love: during this he left his home, passed the night astray, wandered about the fields the next morning, and, at length, disgusted with life, cut his throat with a razor, which he had reserved for the purpose. Having repented of the deed, he retired into the nearest shed, where he remained cold and concealed till the following morning, when he resolved to go back to Vienna, but sunk exhausted on the way. He was brought to the general hospital late the same evening. The wound, four inches long, penetrated through the thyroid cartilage into the pharynx : and it appeared inconceivable how life had been preserved, and how the large blood-vessels had escaped uninjured. The condition of the neck, and the dried blood on the patient's shirt, showed that the wound had existed at least 24 or 36 hours. Dr. Rust united the edges of the divided integument by four or five sutures, and fixed the head forwards. The patient soon recovered from the faint state in which he was on his arrival at the hospital. He 


\section{MR. WOOD ON WOUNDS OF THE THROAT.}

could now speak a little, and swallow so well that doubts arose whether the gullet was actually wounded. He was troubled almost incessantly with cough. Besides the usual emollient remedies, calomel and opium were administered: but as the pulse was feeble, and as the symptoms were rather nervous than inflammatory, venesection was not employed. The patient was flighty and restless. In a fit of rage and desperation, on the fifth day after his admission, he tore off the bandages and loosened the sutures. The wound assumed a sloughy aspect. He lived until the 20th of February, and might perchance have been restored, as later experience authorized Dr. Rust to believe, if in the commencement, without regard to the state of the pulse and the loss of blood, the antiphlogistic plan had been pursued, so as to have entirely prevented inflammation of the air passages and lungs.

A judicial examination of the corpse was instituted. The larynx and pharynx were found completely divided.

"The principal danger of such wounds is to be sought in the subsequent inflammation of the windpipe and lungs. Large doses of calomel, friction of mercurial ointment on the neighbouring parts, cold lotion to the neck, active local as well as general bleeding,in a word, the reduction of life to its lowest pitch are the most certain means to prevent this fatal inflammation. I was never fortunate enough to save 
any one thus wounded, unless where the powers had been almost exhausted by the accidental or prescribed loss of blood. All injuries of this sort have proved fatal when immediate assistance was afforded; and usually the quicker, as the loss of blood was smaller and the patient's strength promised a longer duration of life. Of the latter class several unfortunate sufferers have died, when the windpipe has only been partially divided : whereas I have this day, in the hospital, perfected the cure of such a patient, even under the persistance of symptoms threatening danger, by means of venesection for three consecutive days, so as to produce fainting each time, together with leeches on the neck, large doses of calomel, and a spare diet.

" The uniting of the divided windpipe by suture is not so essential as the ancients supposed, nor so objectionable as modern writers represent. Here, as in general, the middle way is the best, and a single loop appears as necessary in many cases to prevent the descent of the lower portion of the tube, as the employment of three or four sutures is superfluous and prejudicial.

" Further observations and experiments must determine whether, as the above cases seem to teach, it is better, instead of immediately closing by sutures the external wound, to keep it open either totally or at least partially, until the wound of the windpipe 
and other deep parts is healed, so as to allow free vent for any accumulation of pus or mucus."

To this important practical comment I may be allowed to add a few remarks.

In the state of faintness or asphyxia, in which persons are often found after cutting their throats, they are not unfrequently supposed to be dead, and are consequently neglected even by those who ought to judge better*. I have seen a surgeon make a very awkward appearance before a coroner's jury in consequence of this mistake. However desperate the condition of a wounded person may seem, we should in no instance omit the necessary exertions to restore him.

When the windpipe is not divided in a wound of the throat, yet inflammation occurs, the passage for the air is likely to be precluded, and the patient thereby suffocated. This was exemplified in the case of the Swiss soldier. I know no better rule of conduct under these circumstances than that laid down by Dr. Turner in his Art of Surgery. "You are to

- Sapatier justly condemns Lamotte (Traité Complet de Chirurgie, Tom. I. p. 733, Paris 1771,) for suffering a man who had received a wound of the windpipe and cesophagus to be left entirely to nature when a chance of recovery existed. This patient survived the injury three days, and might in the opinion of Sabatier have been restored. A remarkable instance of the same oversight is recorded by Mr. Serre. (Traité de la Réunion immédiate, p. 267, Paris 1830.) 
proceed," he says, "as in the true Angina, not only making all possible revulsion by bleeding, blistering, cupping, sharp clysters; but according to some, and that very rationally grounded, (yet I think very seldom put in execution,) with your knife to divide carefully the membrane between the rimula, or rings of the air-pipe, and introducing a canula below the part obstructed, which is to be there continued until the symptoms remit, and respiration is carried on as before, when the pipe may be taken away, and the wound admitted to heal."*

When the trachea is divided, there is no chance of union by the first intention. For what purpose then are these patients endangered by the employment of sutures? I here allude to the custom of closing the wound by bringing together with stitches the cut surfaces of the integument. If there is a complete division of the windpipe, produced by a simple incision across the throat, unless the lower portion of this canal be prevented from sinking by some means which shall approximate it to the upper portion, the skin is apt to turn inwards, and obstruct the passage by which the air enters. It is true, that in this instance, an additional incision through the skin and subjacent soft parts (commencing at the first cut so as to join it at right angles, and extending along the middle line of the neck towards the sternum to a greater or less extent, according to the degree of sinking of the lower segment of the air-tube,) would

$$
\text { * Vol. I. p. 437. London } 1741 .
$$


prevent them from overlapping the opening, which it is essential to keep clear. But this operation must increase the ugly appearance of the accident, and the subsequent deformity: and, although the use of sutures to maintain in apposition the deep seated parts, is an objectionable proceeding, if it were capable of answering the same purpose, I would rather adopt it than enlarge the wound.

Ambrose Pare relates the following memorable example of the ill effects of stitching the integuments.

-A pastry-cook, who had received a sword-cut of the trachea, had the lips of the wound united by suture. Soon afterwards air insinuated itself into the cellular membrane, and distended the whole body. The face was so inflated that no appearance either of eyes or nose could be perceived. As the pulse could not be felt, he was considered to be more in want of a priest than a surgeon, and extreme unction was administered. The patient was restored by many deep scarifications, which allowed the air to escape.

In a more recent and unfortunate instance emphysema of the upper part of the body occurred to an enormous extent, in consequence of closing the opening in the integuments.

This, however, is not the most formidable result of the use of the needle. In the event of secondary hemorrhage, which, as the preceding histories teach 
MR. WOOD ON WOUNDS OF THE THROAT. 219

us, is not uncommon, suffocation may occur from the want of a proper outlet for the blood, and its consequent passage into the air-tubes. Boyer is correct in saying, that in wounds of the windpipe less danger is to be apprehended from the quantity of blood the patient loses, than from the passage of this fluid into the canal. This accident proved fatal to a patient in St. Bartholomew's Hospital*. It also caused the death of a young woman whose assassination created a considerable sensation in Germany; some difference of opinion having been entertained respecting the case, when the question was referred to the medicolegal authorities of Gottingen,-Whether the wound was necessarily fatal ? These learned gentlemen, in the heat of their discussion, seem to have entirely overlooked that class of events which is designated by the older writers Lethalitas per accidens. For "wounds," says Heister, " become mortal by accident, either by the ill conduct of the patient himself, or by the ignorance or neglect of his surgeon." "The accused person ought to be acquitted, and the surgeon indicted."

\section{CASE+.}

Henrietta Hornbostel, a maid-servant, aged twenty, received a razor wound of the throat on the 17 th of June, 1828, at eleven p. m. Four hours elapsed before medical assistance was obtained; and she had

* See the Lancet, Vol. VII. p. 223, 1825; and Vol. I. p. 764, 1828-9.

+ Rust's Magazine, Vol. XXVIII., p. 322. 1829. 
then lost a considerable quantity of blood. The surgeon found her breathing with a loud rattling noise. The wound extended across the neck, completely dividing the thyroid cartilage at its middle part, and penetrating the gullet. The superior segment of the larynx was drawn considerably upwards. The inferior portion was sunk deeply towards the sternum; but it ascended into view occasionally during certain muscular efforts. The right external jugular vein was wounded: and, as this vessel continued to bleed as often as the patient moved her neck, it was tied. The cut surfaces of the windpipe were appraximated by sutures, which were passed through the tissues immediately in front of the cartilage, but not through the cartilage itself. The wound of the integuments was united by seven sutures and sticking plaster. The head was maintained in a suitable position by a bandage. Air no longer escaped through the wound, and speech was rendered audible; but fits of violent cough supervened, attended with a frothy bloody expectoration. At half past six a. m. there was great restlessness, with difficulty of breathing, a full and hard pulse, and hot skin. A small quantity of blood was therefore taken from the arm. Death took place about an hour subsequently, after an attack of suffocative cough.

Inspection after death.-The wound was united by sutures. It was four and a half inches long, and two inches deep. The thyroid cartilage was completely cut through at its middle part; and one-third 
of the circumference of the pharynx was divided. Excepting the right jugular vein, which was tied, no important vessel or nerve was injured. The windpipe was filled with frothy blood, which had passed far down into the bronchial tubes. The right ventricle of the heart was full of coagulated blood. The full state of the cerebral and abdominal vessels gave no indication of hemorrhage.

In the preface to his "Discourses on the Nature and Cure of Wounds," Mr. John Bell has opposed, with his usual acuteness, the inclination for doing every thing by main force of surgery; and has endeavoured to inspire surgeons with a just and rational reliance on the provisions of nature for the cure of injuries and diseases. But, in his sixth discourse, this excellent doctrine is totally forgotten by the writer; who, although he repeatedly ridicules the excessive care of another author, for stating, " that in a wounded intestine he would not leave even the smallest opening that could admit either chyle or fæces to pass, without stitching it up,"-himself recommends, when the throat is wounded, " to get the parts into fair and neat contact so that not a particle of food nor of foam should escape. The continual draining of the saliva cannot be prevented otherwise than by closing the wound neatly and effectually: it should be closed with a number of separate stitches proportioned to the extent of the wound. The stitches should be neat and firm, through the skin and muscles,- - through all the flesh that can fairly be 
got at, but not through the cartilages. In the interstices of the stitches, should be laid neat slips of black court-plaster, across the lips of the wound: a large flat adhesive plaster should be laid over all to make it firm."

It is necessary to protest against this mode of treatment, since it has been thought worthy of recommendation in some respectable modern works. A French surgeon, who flourished two centuries ago, well observed of a wound of the windpipe, "Labia vulneris inter se junguntur perpetuâ capitis versus sternum inclinatione ac depressione, quæ instar vinculi est et suturæ."*

An interesting history of a patient, aged 55, who divided with a razor the hyo-laryngeal membrane and the anterior wall of the pharynx, is given in the second volume of Loder's Journal. The narrator very correctly attributes the successful result to the judicious treatment employed, and the absence of sutures and unskilful interference with nature.

A grenadier inflicted on himself a severe wound of the larynx and gullet. The integuments were stitched : bandages were applied. In a few days an inflammatory swelling appeared above the sternum; and its formation was attended with dangerous symptoms of suffocation. When pressure was made

* Renati Moreau epistola : extat in opere Thomæ Bartholini de Angina Puerorum, 1646. 
on this swelling, a foul puriform secretion with clots of blood escaped from the wound. The surgeon immediately loosened the bandages, laid open the wound, made an incision through the integuments below, and let out a quantity of stinking bloody matter. Relief soon followed, and the patient got well *.

Walther $\uparrow$ relates an instance of attempted suicide, in which the membrana thyreo-hyoidea was divided with a razor. The larynx was depressed, and all nourishment escaped through the wound. The patient at length found a means of placing his head, which enabled him to take food. He got well rapidly without the use of sutures or plasters.

Schneider $\ddagger$ saw a case in which the windpipe was completely divided, and the gullet wounded. No sutures were employed, and the cure was effected in sixteen days.

M. Fine has given an account of a madman who drew a penknife in several directions through the thyroid cartilage, and wounded the pharynx. The means first adopted to prevent the escape of air through the wound, and to promote its union, occasioned so much distress, that they were soon aban-

* Schmucker's Vermischte Chirurgische Schriften, Vol. III. p. 175. Ed. 2.

+ Med. Chir. Zeitung, 1816. Vol. II. p. 29.

$\ddagger$ Allgemeine Med. Annal. Jahrg. 1818, H. 3. 
doned. The healing process went on uninterruptedly and most favourably when the surgeon was content to follow the simple ways of nature. This case led M. Fine to make the following sensible remark: "As the nature of these wounds varies to so great an extent, the means suited to those which are simple, may sometimes be very prejudicial to those which are complicated; such, for instance, as the bending of the head forwards upon the chest, the uniting bandages, the adhesive plasters, and the attempts to keep the edges of the wound in coaptation: for these means, by opposing the escape of blood or mucus from the larynx, as well as the passage of air through the wound, render breathing very laborious, and thus give rise to congestion of the vessels of the brain and lungs." *

Respecting the advantages which accrue from a considerable and immediate loss of blood after the infliction of these injuries, very opposite sentiments have been expressed by experienced surgeons. It is an opinion held by some, that when persons have bled freely at the time of an accident, or at an operation, inflammation is less likely to supervene. It has been remarked on the other side, that hemorrhage is usually succeeded by a stage of reaction, which will often terminate in inflammation; and that under such circumstances, inflammation is more difficultly contended with, from the previous reduction

* Journal de Médecine, Chirurgie, Pharmacie, \&c. Tom. 83, p. 73. 1790. 
of the patient's powers ; but that, when blood is removed at the onset of inflammation, no such reaction takes place. All the experience that I have had, tends to convince me of the accuracy of Dr. Rust's opinion, and of the fallacy of the observation of those who have regarded this subject in the opposite point of view. I have, generally speaking, found that in all wounds, whether accidental or intentional, recovery is more certain, and is sooner and more satisfactorily effected, whenever much blood has been lost at the onset; and I have so repeatedly witnessed the good effects of this early depletion, that I nearly always hesitate to stop the bleeding of a recent wound. No practice in surgery is, in my opinion, more injurious than the common one, in the treatment of compound fractures, of immediately covering the opening in the integuments, and thus preventing the free discharge of blood. The danger of reaction above alluded to, is not unfrequently produced by the stimulants which officious friends and injudicious surgeons are apt to administer to fainting patients. Where this pernicious practice is avoided, and the loss of blood is ample, the stage of reaction, as far as my experience goes, presents nothing formidable either in itself or in its consequences. 

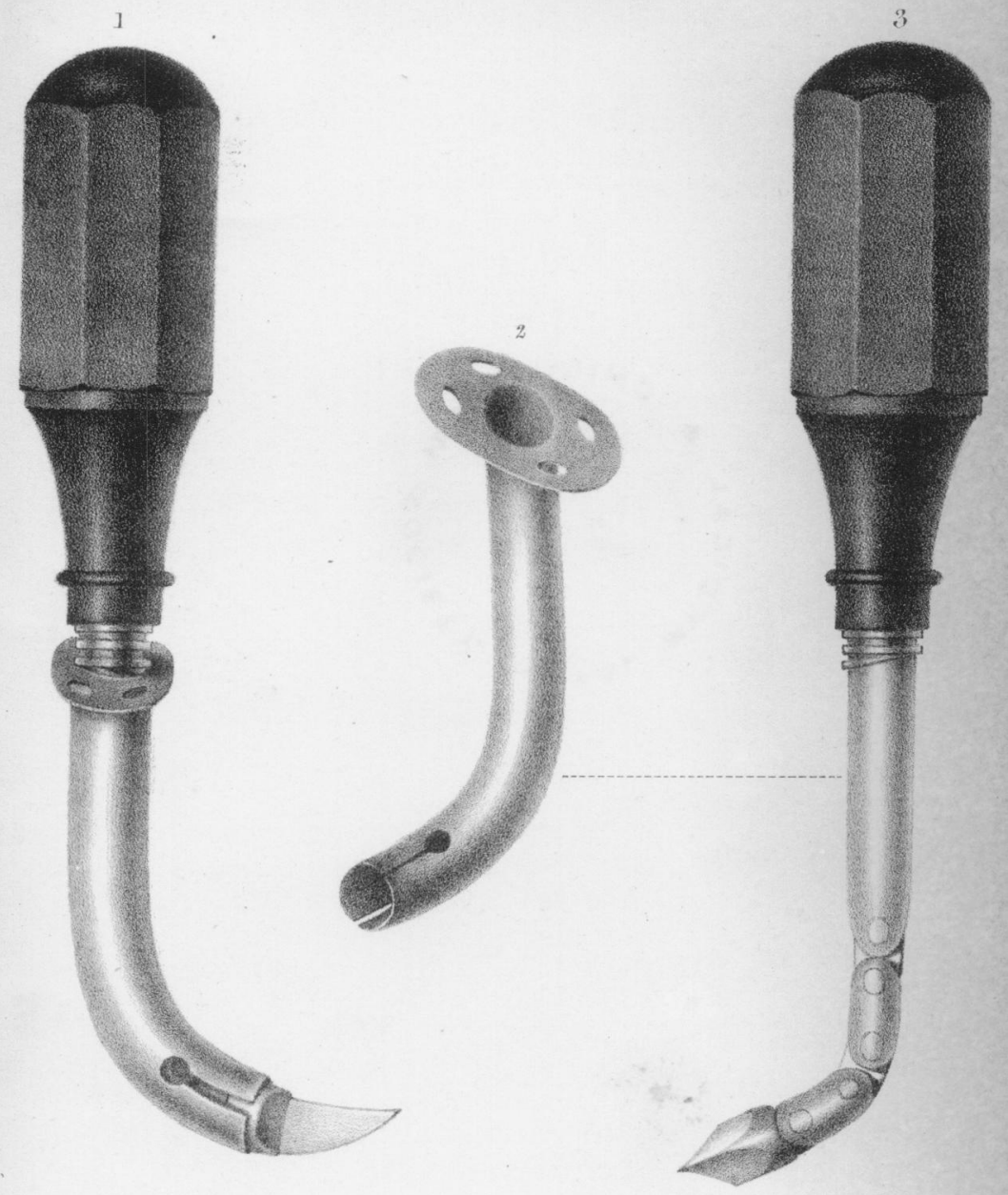